NBER WORKING PAPER SERIES

AGED-CARE SUPPORT IN JAPAN: PERSPECTIVES AND CHALLENGES

\author{
Olivia S. Mitchell \\ John Piggott \\ Satoshi Shimizutani \\ Working Paper 10882 \\ http://www.nber.org/papers/w10882
}

\author{
NATIONAL BUREAU OF ECONOMIC RESEARCH \\ 1050 Massachusetts Avenue \\ Cambridge, MA 02138 \\ November 2004
}

\begin{abstract}
Mitchell is a Research Associate of the NBER; International Foundation of Employee Benefit Plans Professor of Insurance and Risk Management; and Executive Director of the Pension Research Council and Director of the Boettner Center at the Wharton School, University of Pennsylvania. Piggott is Professor of Economics and Director of the Centre for Pensions and Superannuation, University of New South Wales. Shimizutani is an associate professor of Economics at Institute of Economic Research, Hitotsubashi University. Funding for this research was provided by the Economic and Social Research Institute, the Pension Research Council and Boettner Center at the Wharton School of the University of Pennsylvania, and the Australian Research Council. Without implicating them, we acknowledge helpful assistance and suggestions from Yutaka Kosai, Naomi Miyazato, Haruko Noguchi, Junichi Sakamoto, Naonori Yakura, Takeshi Yamaguchi, and seminar participants at the ESRI. This paper was presented at the 2004 International Forum of the ESRI, Cabinet Office, Government of Japan, Tokyo. The authors retain full responsibility for all views contained herein. The views expressed herein are those of the author(s) and not necessarily those of the National Bureau of Economic Research.
\end{abstract}

(C) 2004 by Olivia S. Mitchell, John Piggott, Satoshi Shimizutani. All rights reserved. Short sections of text, not to exceed two paragraphs, may be quoted without explicit permission provided that full credit, including (c) notice, is given to the source. 
Aged-Care Support in Japan: Perspectives and Challenges

Olivia S. Mitchell, John Piggott, Satoshi Shimizutai

NBER Working Paper No. 10882

November 2004

JEL No. H53, H55, I11, I18, I38

\begin{abstract}
$\underline{\text { ABSTRACT }}$
This study explores economic aspects of the market for long term care (LTC) with a special focus on Japan. First, we describe the LTC system in Japan as presently implemented, and we highlight some aspects of the program that are novel and potentially of interest to other countries seeking models for long-term care provision. Next, we discuss alternative projections of Japanese LTC utilization and costs. Finally, since Japan appears likely to experience important shortfalls in LTC in the future, we discuss whether such services might be more efficiently organized and financed under alternate forms of provision.
\end{abstract}

Olivia S. Mitchell

3641 Locust Walk, 304 CPC

Department of Insurance \& Risk Management

Wharton School

University of Pennsylvania

Philadelphia, PA 19104-6218

and NBER

mitchelo@wharton.upenn.edu

John Piggott

School of Economics

University of New South Wales

Sydney 2052, Australia

j.piggott@unsw.edu.au

Satoshi Shimizutani

Institute of Economic Research

Hitotsubashi University

2-1 Naka, Kunitachi-shi

Tokyo, Japan 189-8603

sshimizu@ier.hit-u.ac.jp 


\title{
Aged-Care Support in Japan: Perspectives and Challenges
}

\begin{abstract}
"Veneration of the elderly - a central tenet of both Eastern and Western religious and cultural traditions - obliges family and society to maintain and enhance the well-being of those who are old, particularly if they need assistance.” Garber (1999:166)
\end{abstract}

As global aging progresses, experts have begun to express concern regarding the extent and cost of medical and social services that might be absorbed by a rapidly growing older population. It is in this context that long-term care (LTC) benefits become an important public policy issue with extraordinary fiscal implications as the world ages. This paper explores the topic of aged-care support in Japan, seeking to both help explain the status quo and also to evaluate implications for the future. Of Japan’s 127 million people, almost one-fifth are currently age 65+; the fraction of the elderly, thus defined, is therefore half again as high as in the US, with 290 million people and 12\% elderly, and Australia, which has 19.7 million people and 13\% elderly (USCIA, 2003). ${ }^{1}$ As populations age, there is increasing need for medical care for the frail. Currently, in Japan, around 4\% of the elderly live in nursing homes, a proportion similar to the US (AHCA, 2003; Ikegami and Yamada, 1996).

We begin by describing the LTC system in Japan as presently implemented, and in doing so, we highlight some aspects of the program that are of interest to analysts seeking new models for long-term care provision. Next, we discuss alternative projections of aggregate Japanese LTC utilization and costs.

Following this, we devote some attention to regional differences in entitlement and utilization rates, which will potentially require important cross-subsidization flows in years to come. Finally, since Japan appears likely to experience important future shortfalls in LTC, we discuss possible roles for private provision of LTC insurance services. Economic aspects of the market for LTC insurance are our main emphasis.

\section{Defining Long Term Care}

Though the term "long-term care" is widely used, there is no single agreed-on definition of the

\footnotetext{
${ }^{1}$ In Japan, of the 127 million people, elderly men made up 9.9 million and elderly women 13.8 million; in the US of the 290 million, men were 14.9 million and women 21 million; and of the 19.7 million Australians, elderly men totaled 1.1 million and elderly women 1.4 million (USCIA, 2003).
} 
concept. Medical experts such as Alan Garber (1996) equate the LTC concept with ongoing medical care, particularly that which is designed to comfort those who "suffer from the disabling effects of diseases and injuries that medical treatment can neither cure nor fully relieve” (p. 143). Similarly, health economists such as Edward Norton (2000: 957) emphasize care provided to those with chronic medical conditions who require medical and palliative care. On the other hand, health services researchers such as Nelda McCall (2001: 3) propose a more expansive notion, one that encompasses a "continuum of medical and social services designed to support the needs of people living with chronic health problems that affect their ability to perform everyday activities.” A broad approach to LTC is also taken by healthcare management specialists such as Pratt (1999: 6) who identifies LTC according to the users of these services. Those he defines as people who are physically or mentally dependent on others, and who consequently require health, social, personal, and other services for a sustained period of time.

Since experts differ in what they mean by LTC, it is not surprising that LTC providers are many and diverse, and the product mix included in LTC varies by country and over time. Of course, the traditional nexus of support for the elderly and disabled throughout history has been the family, with multigenerational households exchanging goods and services in a mutual support system. People lacking that option were forced to turn to "poorhouses" financed by charities and other welfare organizations (Pratt, 1999). In the last 50 years, however, many developed countries experienced dramatic fertility declines and rising longevity which contributed to rapid population aging. Combined with a more mobile population, these facts produced a sharp fall in multigenerational co-resident households, making it increasingly difficult for the relatively small working-age cohort to care at home for its long-lived and needy elderly parents/grandparents.

Partly in response, governments in many developed nations have begun to establish, finance, and otherwise support nursing homes, often seen as the institutions most closely associated with the notion of long-term care. Yet the range of services and institutions today associated with LTC is much wider, including the following (Pratt, 1999: 21-22):

- Nursing Facilities: Also known as nursing homes, these are residential institutions licensed by 
government agencies that provide room and board as well as nursing care and some therapeutic services. In the US, a further distinction is made between Subacute Care facilities which are very high-level and usually short-stay nursing facilities; Skilled Nursing Facilities (SNF) which deliver intensive nursing services (e.g. IV treatments, occupational and physical therapy) over longer periods of time; and non-skilled nursing facilities which provide long-term and lower-level medical intervention. ${ }^{2}$

- Assisted Living/Residential Care facilities: This category of residential caregiving facility accepts people requiring assistance with both regular and instrumental activities of daily living.

- Adult Day Care services: These are non-residential programs providing consumers with meals, social and educational activities, and supervision. ${ }^{3}$

- Home Health Care services: Generally these offer consumers services in their own homes for a few hours a week, including a dietary consultation, a modest level of nursing attention, and some therapy. ${ }^{4}$

- Hospice Care: Support is offered by trained but often volunteer staff for those in the final stages of a terminal illness.

Experts often propose that these services and facilities should be thought of as arrayed along a so-called "continuum” of care. In the ideal case, a customer's case would be managed in a coherent and integrated way, and this care would be paid for without gaps. It is worth emphasizing, however, that in practice the institutions and entities which provide care deemed useful and/or necessary for the physically and mentally dependent often are not integrated in a comprehensive way, either in terms of services or financing. Furthermore, even today, much of the care for the long-lived and needy elderly is still provided informally by relatives in both the developed and developing world (McCall, 2001).

\section{Aged-care Provision in Japan}

The current LTC system in Japan is a relatively recent addition to the country’s mandatory national health care system established in 1961. Under the Japanese national healthcare plan, individuals are assigned coverage for medical care based on their job or residential location (Ikegami and Campbell, 1999). Each employer or municipality (prefecture) then must offer mandatory healthcare coverage financed by

\footnotetext{
${ }^{2}$ In many countries, people are classified as being "severely disabled" if they cannot execute at least two of the five Activities of Daily Living (ADLs; Weiner et al., 1994: 5). ADLs involve the ability to bath, dress, eat, maintain continence, self-toilet, and transfer in and out of bed. The typical US nursing home resident requires help with at least 4 (ADLs), which makes it extremely difficult for them to remain in their own homes even with home care (MetLife 2003). In the US, 4.5\% of people 65+ were in a nursing home in 2000 (MetLife 2003), but the percentage rose rapidly with age: $18 \%$ of those $85+$ were in a nursing home. Nursing home costs in 2002 in the US cost \$50-60,000 annually, just for room and board (MetLife 2003).

${ }^{3}$ A simplified list of the so-called Instrumental Activities of Daily Living (IADLs) includes preparing meals, doing housework, taking medication, shopping, using transportation, managing money, and using the telephone (Powell, 1999).
} 
premiums levied on household heads (in the case of the community-based plans), or shared half by employers and half by employees (for company-based plans; Ikegami, 2003). Self-employed workers are required to pay the entire healthcare premium themselves. National fee schedules are set by the government and apply to all providers in Japan; medical care providers are further prohibited from balance billing (Ikegami, 2003). In 2002, for instance, fees for medical procedures were cut by the central authority by 1.3\% overall, and by 5-30\% for some services such as CT scans and MRIs. Drug fees are also set centrally and were reduced 5\% in 2002; drug competition is permitted only as long as prices are below the centrally-set fee (Ikegami, 2003).

When citizens reach retirement age, they are required to join the Citizens’ Health Insurance plan (CHI), a decentralized system providing various levels of home care and also institutional care. As part of this system and particularly from 1973 on, the frail elderly were entitled to free hospitalization even if they did not require intensive medical care; as a consequence, by 1993 the elderly accounted for almost half of all hospital beds and one-third stayed for more than one year (Campbell and Ikegami, 2000). This phenomenon, termed “social hospitalization,” was the target of reform under the Gold Plan of 1989 and revised in 1994. Under this initiative, the central government instituted efforts to boost the number of nursing home slots, adult day-care centers, and home health aid providers. At the same time, municipalities were given a key role in setting eligibility standards and determining who was entitled, in keeping with public assistance philosophy. It represented a formal acknowledgement that care for the frail elderly was a problem of growing national consequence.

The present Japanese LTC program was introduced in 2000, with four key objectives enunciated by the Japan Ministry of Health, Labor, and Welfare (JMHLW, 2003a). First, the approach sought to reduce the burden of home care of the elderly, a burden traditionally borne by women. In other words, this program represented a major shift in the responsibility for elderly care away from the family, and toward the state (Campbell and Ikegami, 2000). Second, the new system sought to make more transparent the

\footnotetext{
${ }^{4}$ In the US, paid home care services were used by $28 \%$ of people $50-64$ needing help with ADLs, and $48 \%$ of those age 75-84 (MetLife 2003). Hourly rates for home health aides averaged \$18/hour in 2003 (MetLife 2003).
} 
relationship between benefits received and premiums paid. Third, the new program was designed to integrate what had been a vertically-divided system of health, medical, and welfare services operating relatively independently, so as to provide a means by which customers would receive comprehensive services from a variety of institutions of their choice. Fourth, by separating long-term care from health insurance coverage, the new insurance program sought to reduce the number of "social hospitalization" cases where elderly were hospitalized simply because of a lack of viable alternatives.

\section{Program Benefits}

Focusing first on system benefits under the Japanese public LTC system, the program is explicitly intended to provide both in-home services (at-home care) and also services at facilities (institutional care). ${ }^{5}$ All persons age 65+ are eligible, along with people age 40-64 with health-related disabilities. Eligibility is determined based on condition, rather than income and/or assets, and it must be reevaluated every six months (Campbell and Ikegami, 2000).

To receive LTC benefits, an individual must undergo a lengthy and information-intensive disclosure process, beginning with application to an expert committee which collects extensive information and applies a computer algorithm to 85 data inputs, including the applicant's income, assets, and health information (Ikegami, 2003). Facilities-based services are offered only to customers who are certified by the LTC expert committee as needing such care based on health status. These committees must make a screening determination based on the opinions of doctors within 30 days of application (Campbell and Ikegami, 2000). Though standards for long-term care requirement certification are intended to be nationally uniform and objectively determined, in fact, each municipality appoints its own examiner group comprised of physicians and other care providers. It is worth noting that municipal government officials having budget responsibilities do not serve on these examiner committees, which may diminish incentives for cost-cutting (Campbell and Ikegami, 2000).

At the time a person is certified in need of LTC, he is further determined as falling into one of

\footnotetext{
${ }^{5}$ Unless otherwise noted this discussion is adapted from JMHLW (2003).
} 
health condition groupings identified as Care Levels 1-5, versus “support required.” 6 Benefit entitlements correspond to each care level, though services provided may vary across regions. On the whole, long-term care "welfare" facilities mainly focus on the consumer's activities of daily living, while health facilities are mainly oriented toward rehabilitation. LTC medical facilities are mainly health-care delivery institutions. As an example, the financial value accorded to in-home benefits and home-visit outpatient services varied in 2003 from $¥ 62,000$ - ¥358,000/month, and for short-stay service, people are entitled to 7-42 days in a facility every 6 months. Facility benefits are determined according to the level of long-term care required. After the municipality board assesses the customer's eligibility and level of care needed, he is referred to a care manager who then consults with the customer as well as the patient's doctor. After the customer approves the care plan, the care services actually delivered; customers are permitted to switch care managers at will.

Two types of services are offered under the LTC program. In-home services include a variety of offerings including (1) home-visit/day services (home-visit long-term care, home-visit bathing, home-visit rehabilitation, day rehabilitation (day care), home-visit nursing care, day service, welfare devices leasing); (2) short-stay service/short-stay care; (3) in-home medical care management counselling; (4) care service for the elderly with dementia; (5) care service provided in for-profit private homes for the elderly; (6) allowance for purchase of welfare devices; and (7) allowance for home renovation (handrails, removal of level differences, etc.). Services at facilities are described according to three types of nursing homes: (1) long-term care welfare facilities for the elderly (special nursing homes for the elderly); (2) long-term care

\footnotetext{
${ }^{6}$ The categories of care are as follows: the first or lowest care level category is the so-called "Support Required" condition; here the consumer lives independently but requires any assistance for Instrumental Activities of Daily Livings (IADLs) such as taking medication and phone calls. Above this, five levels of "Care Required" are distinguished, all of which require that the consumer cannot live independently but requires care in basic Activities of Daily Lives (ADLs). Care Level 1 is defined as having more IADLs than the "Support Required" category; this individual would require partial care for daily living and care for IADL. Care Level 2 is defined as having additional need for help with ADLs in addition to the problems defined above. Care Level 3 requires more help with both IADLs and ADLs than Care Level 2 and the individual would require total care. Care Level 4 is defined as having all previously described conditions along with worse functioning in the ADL area; such an individual would find it difficult to live without care. Care Level 5 is defined as finding it impossible to live without care, and having worse ADLs than Care Level 4 . To ensure uniformity of certification, primary judgment is based on estimating a consumer's required "minutes of care" required per day as well as other indicators of dementia. These are described as typical requirements for each care level: Care Required: 25-32 minutes; Care Level 1: 32-50 minutes; Care Level 2: 50-70
} 
health facilities for the elderly; and (3) long-term care medical facilities for the elderly. The last type also includes sanatorium-type wards as well as wards for elderly patients with dementia, and hospitals with enhanced long-term care service provision. Medical care, per se, is not included in the LTC program but instead is offered under the national healthcare system.

Rates for all covered LTC services are set by the JMHLW and are based on the units concept. The Ministry has allocated a given number of "units" to particular services, where a unit varies with the service involved and by region (taking into account some degree of regional wage differentials of service providers). A unit’s value is currently set at about $¥ 10$; this will be revised every three years. For example, 231 units are associated with home-help service care ranging from 0.5-1 hour (as of April 2003), regardless of the actual level of care administered. This means that the price of home-help service in a typical area is $¥ 2,310$. The number of units assigned to institutional care depends on the customer’s required care level. For example, in a typical long-term care welfare facility, 959 units per day are allocated to a Care Level 5 case, and 677 units are associated with a day in a Care Level 1 environment. Further detail on the unit allowances for different types of care is provided in Table 1, arrayed by the condition of the elderly person.

\section{Program Financing}

Turning to financing, the Japanese public LTC system is operated as a pay-as-you-go program, financed by both earmarked premiums levied on insured persons and general tax revenue. Half of the program costs are paid by premiums assessed on workers (age 40+) and their employers as well as retirees (deducted from their public pensions); these premiums are collected by municipalities. ${ }^{7}$ Workers under the age of 40 do not currently pay premium taxes into the LTC system.

It is worth emphasizing that the LTC premiums are means-tested: for example, the "basic" premium is ¥3,293/month for “Category 1” individuals (JMHLW, 2003), but it is higher for other categories of individuals. Category 1 individuals must be age 65+, among whom some are exempted from municipal taxes by virtue of having very low income; the group also includes those on public assistance,

minutes; Care Level 3: 70-90 minutes; Care Level 4: 90-110 minutes; Care Level 5: Over 110 minutes.

${ }^{7}$ A recent study by Komamura and Yamada (2004) offers evidence that much of the employer's contribution is also 
people with confirmed disability, and widows and widowers whose total income in the previous year is less than 1.25 million yen. Category 2 persons are those age 40-64 who are insured by the national health insurance system. A Category 2 individual having income under ¥2.5 million annually pays a LTC premium of 1.25 times the "basic" amount, while an individual with income over that threshold must pay a premium set at 1.5 times the "basic" amount. ${ }^{8}$ Premiums also vary across municipalities; after setting premium levels in 2000 and revising them in 2003, the expectation is that premiums will be revised every three years going forward.

Annual LTC expenditures in 2002 totalled $¥ 5.2$ trillion (AJFNHIO, 2002). This is composed of premiums worth just over half of a percent of workers' annual earnings covering about one-third of the total program cost (Campbell and Ikegami, 2000). Premiums paid by the elderly (age 65+) cover 17\% of the program's costs, and the rest of the costs are paid by the central government ( $25 \%$ of the cost), prefectures (12.5\%), and municipalities (12.5\%).

In addition to premiums, eligible consumers must pay additional out-of-pocket amounts for LTC services and care. An eligible person must pay a 10\% co-insurance amount for each insured service. For instance, if home-help service care is priced at $¥ 2,310$ per hour, the customer would pay $¥ 231$ for that service and the municipality pays the rest. The customer is also responsible for meal charges when in a nursing home. These co-pays are set by service and type of care, and vary depending on the consumer's care level but not his income level. After spending up to a threshold, the consumer is responsible for $100 \%$ of any additional costs until hitting a stop-loss threshold called the "high-cost long-term care service limit." Above that threshold, additional expenses incurred by the consumer are covered by the LTC program at $100 \%$.

The stop-loss threshold is reduced for low-income consumers, in some cases by more than half. ${ }^{9}$ In 2003, for instance, a Care Level 3 consumer faced an out-of-pocket limit for care services of 26,750

\footnotetext{
paid for by workers, shifted to employees in the form of lower wages.

${ }^{8}$ In addition, these premiums may be exempted and/or reduced “at times of emergencies" according to the JMHLW website.

${ }^{9}$ An old-age welfare pension recipient has an out-of-pocket limit of ¥15,000/month; a municipal tax-exempted
} 
units/month, with one unit equal to ¥10. In other words, he was eligible to use care services worth $¥ 267,500$ in a month simply by paying $¥ 26,750$. For meals, the standard charges amounted to $¥ 23,400$ /mo (or $¥ 780$ /day). If the cost of services consumed exceeded this limit, the consumer would have to pay for all the additional services, up to an out-of-pocket maximum of $¥ 37,200$ /month for a non means-tested consumer. After that point, all additional costs would be paid by the system.

\section{Public LTC Service Utilization and Cost Projections}

To evaluate how the public component of Japanese LTC may evolve over time as the population ages, it is useful to assess models of utilization and cost projections. In Japan, as elsewhere, LTC projections are fraught with uncertainty. Often analysts take existing utilization patterns and multiply then by population projections, though this can result in imperfect projections because of changes in demand due to subsidized care. There may also be changes in demand if copays and deductibles are raised, or if the existence of the LTC system contributes to the rehabilitation and recovery from illness and injury. In addition, some experts project substantial declines in future utilization rates as a result of more resilient older populations. For instance Fries (1980) contended in a controversial but influential paper that “[e]xtension of adult vigor far into a fixed life span compresses the period of senescence near the end of life.” Subsequent research offers additional empirical support of this view including Lubitz et al. (2003) who suggests that longer lifespans may not necessarily boost healthcare spending per capita. In any event, future morbidity declines will probably not offset much of the cost increases attributable to the rise in the fraction of the population that is elderly (Garber, 1999).

The All-Japan Federation of National Health Insurance Organizations (AJFNHIO, 2003) estimated that 3.7 million persons were certified as in need of some LTC in 2003. Of these, only 2.7 million received care, with at-home care users totalling 2 million (58\%) and institutional care users totalling 0.7 million (20\%). Projections of possible future LTC need and utilization are offered by the Japanese Ministry of Health, Labor, and Welfare (JMLHW), which relies on methodology developed by the Research Group on Elderly Care and Support Systems for Autonomous Living (the precise methodology has not yet been

person’s limit is $¥ 24,600 /$ month; and a regular taxpayer has a limit of ¥37,200/month. 
explicated formally so the resulting estimates are quasi-official). It is known that the office estimated the number of demented elderly for every five years going forward, from 2005 to 2045, and it also estimated government net expenditures (aka “Evaluation Payments”) for 2005, 2015, and 2025.

Kishida (1998) estimated the number of elderly needing care using a different model, and it indicated far more shortfalls than found by the MLHW. Relying on 1993 incidence rates from the MLHW, he concluded that more people would require care over time than the government estimated. In fact, by 2020 he estimated that the number needing care would rise to 4.8 million (assuming a 3\% annual growth rate) and that the population needing care would grow until 2030. He used the "current” unit costs of LTC in these projections, and obtained overall net cost estimates higher than the JMHW's 1995 estimates: the Ministry had forecast costs of $¥ 4.2$ trillion for 2000 , while Kishida’s projections totalled $¥ 8.5$ trillion. In addition to differences in projected numbers of users, Kishida took a more comprehensive view of cost; he included living expenses for elderly and imputed a value to the care provided by family members to the elderly (no breakdown was provided, however, of exactly comparable numbers).

Table 2 assembles some future projections of elderly eligibles and costs of LTC in Japan. These rely on historical data for the number of elderly requiring LTC in Japan during the 1990s (see Table 3). Of course, utilization patterns could well be higher since the current LTC program only went into effect in 2000; in view of population aging and likely increased demand for LTC services, an extrapolation of historical trends may underestimate future LTC costs. Table 4 reports the official projections of the number of elderly expected as of 2025 as well as the number of frail, bedridden, weak, and those expected to need LTC services at that point.

Using these numbers, one may try to bound the range of estimates for aggregate LTC costs in Japan by 2025. On the assumption that care prices remain constant over time and that the share of users does not change, total costs would rise by virtue of population aging alone from $¥ 5.2$ trillion currently to reach ¥9 trillion (AJFNHIO, 2002). If, instead, at-home and institutional user prices are fixed, but the share of at-home users rises at historical rates, projected expenditures would exceed $¥ 10$ trillion. Further, allowing both the number of at-home users and the price of home care (but not institutional care) to rise at historical 
rates would boost total estimated costs to ¥26 trillion. Finally, the estimates would be much higher if both price and utilization rates for institutional users were projected to rise at historical rates. Microeconomic panel data will be required to refine these projections, permitting the development of statistical transition matrices between health status categories influencing healthcare utilization and cost patterns. ${ }^{10}$

\section{Regional Differences in Dependency, Capacity, Utilization and Costs}

One interesting aspect of the Japanese LTC system is that some aspects are highly centralized, while others are quite decentralized. The central government requires that LTC services can only be provided by non-profit nursing homes and hospitals, whereas home-care services may also be provided by private for-profit firms. Prices of services and units of care are also set by the central government. Each municipality - of which there are 3,200 - then decides which people are eligible for what kinds of care. ${ }^{11}$ Municipalities set premium levels for LTC at the local level, and they also collect premiums from workers and retirees in their locales. And finally, the "insurance carriers” of this long-term coverage are the municipal governments which in turn approve the care providers. In the case of at-home care, these include local government service organizations and non-profit outfits and more recently, for-profit firms. Since fees are set centrally, providers are intended to compete based on quality of care, though it is not yet known whether consumers and their families are able to judge, and act on, the information provided.

A consequence of this “decentralized yet centralized” approach is that there are important regional differences in provision and capacity. Each community has different income and age structures, which results in sharply different utilization patterns by region, as is shown in Figure 1 and Table 5, derived from data provided by the All-Japan Federation of National Health Insurance Organizations (AJFNHIO, 2003). ${ }^{12}$ While the percentage of elderly as a fraction of the Japanese working-age population (defined as 15-64) averages $31 \%$, this dependency ratio varies across prefectures from a low of $19 \%$ to a high of $43 \%$. Also there are substantially different concentrations of elderly requiring services across the country, meaning

\footnotetext{
${ }^{10}$ In the US, for example, Robinson (1996) has developed transition matrices that differ by age and sex, using panel data on the elderly for the period 1982-1989.

${ }^{11}$ Some municipalities are allowed to form a union to operate the LTC scheme jointly.

${ }^{12}$ These figures are derived from Statistics Bureau (2003).
} 
some local areas are more likely to confront serious financing problems than others. For example, elderly entitled to LTC services amount to only $4 \%$ of the working-age population overall, and $14 \%$ of the elderly population. Nevertheless the range is again large, from 2 to $7 \%$ of the working-age group, and from 12 to $18 \%$ of the elderly. Figure 1 groups the 47 Japanese prefectures by region, and the graphic makes clear that there is substantial regional unevenness in terms of where the elderly live, with higher concentrations in the southern regions of the nation and lower rates in the Kanto region. Entitlement ratios, on the other hand, are more even suggesting some implicit rationing.

Evidently the elderly in Japan, as in many other nations, are not dispersed evenly across the land. This is, in part, because many elderly remained behind in the rural sector when their children moved to the cities in search of work. In the future, the elderly may become increasingly concentrated in a few prefectures: for instance, Doteuchi (2003) suggests that the largest growth in elderly populations will be concentrated in the nation's top major metropolitan areas, particularly Tokyo and Osaka. Such concentration would raise concerns, since elderly urban housing is often crowded and of low-quality, it may be ill-suited for those with physical limitations, and it may be inappropriate for those needing frequent services and attention. ${ }^{13}$

Another important point to note is the substantial differences in terms of LTC capacity across regions, particularly regarding the number of beds available in institutions. Figure 2 and Table 5 indicate that beds per 1000 elderly average 32 overall, with a high of 50 and a low of 22; the ratio of beds to eligible elderly averages 238 per 1000, but the low is 169 and the high is 319. Interestingly, the capacity is highest per capita in the Chubu region, and also in the south of the country (AJFNHIO, 2003).

Utilization ratios are also of interest, insofar as they reflect regional differences which will likely translate into uneven cost patterns across the nation. Figure 3 indicates the regional variability in institutional care users per elderly, which averages a 3\% rate overall, with a range from 2 to $5 \%$. The highest is observed in Okinawa. An even larger range is observed for at-home care users, where the national average of $8 \%$ covers the $5-10 \%$ range. Here too, it appears that utilization rates are lowest in the Kanto 
region, and highest in the south of the country, particularly Miyazaki.

A related consideration regarding the current decentralized LTC system is that it appears to be suffering excess demand for its services. Kishida (2002: 269) wrote that "since LTC insurance was initiated, there has been a sharp increase in applications to these special skilled nursing homes, and waiting periods of 6 months to one year are not unusual.” Asahi Shinbun (2003) reported that a survey of prefectural governments found over 200,000 elderly people were on waiting lists seeking entrance to special care homes, among the subset of offices keeping records (only 27 of the 47 responded with data). The latter article also found substantial shortfalls in 2001: residences for those 65+ who could not care for themselves were operating at 97 percent capacity, and the national capacity was only for 314,000 residents in total. Ikegami (nd) indicated a substantial rise in the fraction of the elderly population certified as needing care over time, from $10.5 \%$ in 2000 to $14.1 \%$ in 2002, higher than the $12 \%$ ratio used for planning purposes. Of those certified, the percentage actually receiving benefits rose from $76.1 \%$ in 2000 to $77.8 \%$ by 2002 , with the remainder waiting to be accepted in institutional facilities. These figures suggest that as the population becomes more aware of the benefits available, demand will rise.

If Japanese LTC services were priced in such a way that they reflect economic scarcity, the economist would expect that capacity differentials would result in higher fees across regions of the country. Yet prices are not set by markets; rather, the government sets national service fees and alters these only every three years. This results in a very low degree of variability in fees per user across the country (Figure 4), with the average institutional charge per user of institutional services totalling about $¥ 43,000$ annually and at-home care fees for homecare users amounting to about $¥ 11,000$ annually. Standard deviations around these numbers are quite small, on the order of $¥ 900-1,000$. This confirms that substantial differences in utilization and capacity are not reflected in regional fee differentials.

It must also be noted that regional disparities are also influencing the revenue side of the program. Ikegami (2003) has argued that high levels of joblessness contributed to lower LTC system revenues, particularly in the prefectures hardest hit by the long Japanese recession. Furthermore, the poor elderly

\footnotetext{
${ }^{13}$ Of course this may still be preferred to remote rural dwellings.
} 
participants pay no premiums, due to either evasion or waivers (currently about $40 \%$ of the total), and this group is not necessarily evenly spread across the country, either. Consequently, there is increasing awareness of the need for geographic cross-subsidization, and the federal government has promised that $5 \%$ of the program's budget will be used to adjust for differences in municipalities' financial capabilities.

\section{Multivariate Analysis}

To further analyze observed cross-sectional fee and utilization patterns, we next turn to a multivariate analysis of the determinants of LTC entitlement and utilization patterns across Japanese prefectures. Three dependent variables are selected for analysis: elderly LTC entitlement rates, utilization rates for institutional care, and utilization rates for at-home care. These are available at the prefectural level, and we relate them to a set of explanatory variables also measured at the prefectural level: population density, wages of care-givers, and local care capacity. ${ }^{14}$ Our goal is to evaluate, in particular, whether entitlement and utilization rates vary with population density; are higher in rural vs urban areas; are responsive to proxies for care prices; and vary with capacity indicators. The particular functional form we use is as follows:

$$
\text { Dep } \operatorname{Var}_{\text {it }}=\mathrm{f}\left(\text { Density } y_{\mathrm{it}} \text {, Healthcare salaries, Area income, Capacity }{ }_{\mathrm{it}}\right)
$$

where i refers to the prefecture, and t refers to the year of the data (2000 and 2001 prefectural-level data were used in the analyses). Density refers to the number of residents in that prefecture (per km squared); healthcare salaries represent earnings plus bonuses in the healthcare sector by prefecture; area income refers to the monthly average earnings (including bonuses) by prefecture; and capacity refers to the ratio of long-term care and hospital beds to the number of elderly.

Results appear in Table 6, where we first control only on density, healthcare sector salaries, and income; thereafter, we add a set of capacity regressors. Focusing on column (1), we note that entitlement rates are significantly higher in more densely populated areas, holding other things constant, which contradicts a common perception that rural areas have higher percentages of elderly who are eligible for

\footnotetext{
${ }^{14}$ The prefectural area and population statistics are available at JMPMPAPT (2003). The price per person of institutional and at-home care is derived from JMHLW (2003).
} 
LTC. The finding may indicate that the urban elderly can remain independent more readily, due to reliance on friends, neighbors, and offspring, than can their rural counterparts. We also see that entitlement rates are significantly lower in areas with higher wages for healthcare sector workers, suggesting that entitlement decisions may respond to costs of providing the care. Entitlement rates are also significantly lower in prefectures with higher incomes, which may proxy for better health among the well-off, or it may also reflect a negative income effect: that is, those who can afford it are more likely to avoid LTC. These findings suggest that efforts to project future demand for LTC should take into account not only growth rates of the elderly population, but also the likely impact of future increases in income and care costs. The results also indicate that eligibility rates are higher, the greater fraction of the population age $75+$; this is reasonable in view of higher disability rates among the more elderly. Column (2) indicates that these findings are robust to the inclusion of capacity indicators, captured here by the number of LTC and hospital beds per 1000 elderly. It is interesting that LTC bed availability is positively and significantly associated with entitlement patterns, but non-LTC bed availability is not statistically significant.

The empirical relationship between at-home and institutional utilization rates is reported in Columns 3-6. Focusing first on the at-home care equations, Columns 3 and 4 suggest that, again, more densely populated areas have higher utilization rates for home care. There is a strong and significant negative relationship between healthcare salary levels and LTC utilization, ceteris paribus, which implies that utilization responds to the price of care. Area income is negative (though less statistically significant), which may reflect the fact that higher-income eligibles face a higher cost of care (are less subsidized) than lower-income eligibles. After controlling on bed capacity, utilization proves to be positively associated with LTC beds, but not with regular hospital bed capacity. Columns 5-6 report our analysis of institutional utilization rates, where many of the patterns just reported are reiterated. In more urban areas, institutional care utilization rates are positive, as is the effect of higher percentages of people age $75+$. While healthcare sector earnings are less statistically significant, income levels in the prefecture remain negative. LTC 
utilization is positively and strongly related to LTC bed capacity, while non-LTC bed capacity is not. ${ }^{15}$

\section{Socially versus Privately-Provided LTC: The Arguments}

There is an ongoing and contentious debate in the literature over who should pay for long-term care and how it should be delivered. ${ }^{16}$ Some believe that private-sector insurers can develop and market insurance products that efficiently provide the needed protection against the possibly catastrophic costs associated with having to go into a nursing home. Others take the position that LTC insurance cannot be provided in a competitive market, arguing that a governmental entity is required to mandate and perhaps provide LTC in a national social scheme.

Many who favor the social insurance approach argue that LTC should be provided via a central delivery system paid for by mandatory premiums (taxes dedicated to the LTC program). Proponents of social provision offer several arguments to support their case:

a) They contend that consumers are underinformed of the risks and costs associated with LTC, so they must be protected from failing to purchase LTC insurance;

b) A private LTC insurance market suffers from adverse selection: people who know they require care would tend to buy insurance coverage, driving up premiums for the rest of the population and destroying the risk pool;

c) A private LTC market suffers from moral hazard: people might overuse LTC services if they had insurance, driving up premiums and producing a market breakdown;

d) LTC costs are often catastrophic and many people cannot afford to buy insurance to cover them; and

e) It is unfair to require the elderly to sell their homes and spend down all their assets if become frail.

Of course, economists may agree that market failures exist, but many would contend that these could be addressed by making private markets work better, rather than requiring the government to offer a centralized LTC system. For instance, misinformed consumers could be better apprised of LTC costs, enhancing demand for privately-provided insurance products. In other cases, such as adverse selection, mandating participation in a LTC system could help preserve the risk pool without having the government provide these services centrally. In order to combat moral hazard, however, so people do not overutilize care, it may be necessary to establish strict requirements for care provision as well as deductibles and co-insurance. And finally, the equity arguments ( $\mathrm{d}$ and e above), could imply some need for vouchers or

\footnotetext{
${ }^{15}$ We do not control on area-specific eligibility rates in this equation since these depend on capacity constraints.
} 
low-income subsidies: here again, however, the government need not set prices nor dispense services directly.

By contrast, those who stress the need for market approaches to LTC emphasize several distinct arguments to support their case, including the following:

a) People might be able to self-finance LTC by saving for their own old age, by liquidating private assets (including housing equity) to cover costs, or by receiving care from their families (which many elderly would prefer);

b) Privately purchased LTC insurance coverage would permit tailoring of care to consumers' particular needs and wishes, better than a single menu offered by government;

c) Observed low demand for private LTC might be the result of "crowd out" - that is, consumers may believe that government "safety net" programs will care for them if they become indigent, so they fail to make private provision;

d) Government care, perceived as "free," would boost inefficient utilization, whereas privately-purchased insurance might mitigate this tendency with deductibles and co-insurance;

e) Subsidized government provision can cause inefficiencies in both the labor and the LTC markets, and evasion associated with redistributive taxation.

In other words, a market-based approach to LTC provision would propose that private provision could be more efficient than a government at establishing prices and quantities of long-term care services sold. Some concerned that the poor could end up without care would likely favour a voucher system, so that a minimum level of care could be provided to destitute consumers requiring LTC. On the other hand, resulting low benefits and restrictions on access would mean that most consumers would still have to pay for care at prices reflective of economic resource costs. Such an approach, if combined with mandatory participation, would still embody some inefficiencies, but it could offer consumers incentives to seek lower-cost alternatives and to undertake more self-provision, either through saving or insurance, than would be the case otherwise.

\section{Prospects for Private LTC Insurance in Japan}

In view of the catastrophic nature of LTC expenses, it is interesting that the private insurance market plays such a small role in Japan, as well as in many other developed nations. For instance, Garber (1999) argues that the "most striking feature” of the US health care system is its failure to develop much of a private insurance sector. Only one in five married couples deemed to be able to afford private LTC

\footnotetext{
${ }^{16}$ See for example Garber (1999), Pratt (1999), and McCall and Korb (2001).
} 
insurance in the US, for instance, is adequately protected against this risk in retirement (Merlis, 2003). Many attribute this shortcoming to the pervasive influence of public programs such as Medicare and Medicaid, which tend to crowd out privately-provided LTC insurance (Doerpinghaus and Gustavson, 2002). The wealthy tend to self-insure, leaving the middle class as the group potentially most interested in private LTC coverage. It is widely believed, however, that this middle group thinks that their LTC will be met through Medicare (which is not correct), so hence they do not purchase individual policies. Better marketing by insurers could correct this misinformation, but this has not happened to date to any large degree.

\section{Future Demand for Private LTC Insurance in Japan}

Several factors will influence Japanese demand for LTC in future years.These include developments in health care and technology, and changes in length of time during which the elderly population experiences periods of frailty. Their net impact on LTC demand is difficult to predict. Perhaps the greatest unknown is how attitudes in Japan will continue to evolve given what is widely recognized as a fundamental change in the society's approach to care for the elderly. On the one hand, establishing an entitlement-oriented LTC program in Japan will surely make it possible for older persons to accept services without social stigma. On the other hand, demand for LTC may not grow as quickly as the elderly population. This is what has occurred in the US due to falling disability rates in the older population. Indeed, reduced elderly morbidity may mean that more people are able to care for their spouses in a nonmarket setting, thus reducing the demand for institutional LTC (Lakdawalla and Philipson, 2003). In addition, levels of wealth will surely influence the demand for care, by directly shaping older consumers' ability to pay for care, and indirectly by influencing younger workers’ ability to pay for rising premiums associated with the national mandatory system.

Another key factor affecting the demand for LTC will be the attractiveness of these services to elderly consumers, particularly institutionalization, as compared to the alternatives of at-home care or residential living of some other sort (Pauly, 1990). In other words, people may be less likely to opt for institutionalization if attractive and low out-of-pocket cost substitutes are available. The medical literature 
on this topic is discouraging, since it suggests that home care is not a particularly effective substitute for nursing home care. One well-designed experimental program in the US, known the Channeling Demonstration project, showed that assigning expert case managers to help frail customers remain in the community increased costs and patient satisfaction, but did not forestall health deterioration, nursing home admission, or death (Garber, 1999:148). From a quality-adjusted perspective, then, the economics profession has concluded that the price elasticity for nursing facilities among the very ill is fairly small. On the other hand, some aspects of nursing home demand do appear to be price-sensitive, particularly among those in nursing facilities for short stays (Garber and MaCurdy, 1992).

In Japan's case, a variety of price elasticities for different types of institutional care were evaluated by Noguchi and Shimizutani (2002), who examined the determinants of exit and reentry from medical facilities (requiring substantial medical input), versus welfare facilities (providing room and board, but little medical intervention). Using a unique dataset on Japanese nursing homes from Kaigo Service Shisetsu Zigyousho Chousa (Survey on Care Service Providers) conducted by the government in 2000, they showed that a one percentage point rise in consumers' cost of care increased their probability of returning home by only 0.04 percentage points from long-term welfare facilities. The estimates were much larger, 3.7 percentage points, for exits from health facilities. It is also interesting that they found large price elasticities with respect to re-hospitalization probabilities: a one percentage point increase in consumer costs cut re-entry to a health care facility by 3.3 percentage points, and by 1.9 percentage points to a medical care facility. Evidently, at-home care is a substitute for some institutional care, but care in medical institutions is complementary for nursing home care. It is also apparent that the elderly in relatively lower care levels, who face higher self-burden in the event of needing long-term care, also tend to be re-hospitalized if they lack family members with whom they can live. Consequently, policies that address the residential patterns of those who are "socially hospitalized" in Japan could well focus on that category of elderly consumers. Finally, the research study found that the price elasticity with respect to duration of stay in nursing homes is -1.7 percentage points for long-term care welfare facilities, and -1.8 percentage points for health facilities. These rather large elasticities imply that price policy may be effective in inducing clients to reduce 
consumption of institutional care in favor of at-home care.

Another issue of relevance in this arena is whether people prefer public and/or nonprofit care providers, versus for-profit providers. In the Japanese context, Noguchi and Shimizutani (2003) found that $40 \%$ of the providers of at-home care are situated in the for-profit sector. Evidently, the introduction of public LTC insurance in Japan did not foreclose the entrance of profit-oriented firms to the at-home services market. The evidence also suggested that households with higher care needs were more likely to choose a nonprofit provider. This is partly in response to the legal requirement that these firms are the only ones permitted to provide medical and institutional care, and also a result of the fact that nonprofits were early participants in the marketplace, having been permitted to operate prior to the LTC reform. While for-profit providers are therefore disadvantaged, the study found that households with greater knowledge of supplier choices were more likely to select for-profit firms as caregivers. This suggests that, over time, greater information about the positive aspects of the for-profit firms will render the at-home care market more competitive.

\section{Future Supply of Private LTC Insurance in Japan}

The supply of private LTC is deeply influenced by the probability of adverse selection. To some extent, underwriting in private markets should reduce adverse selection, but it is important to note that the assessment technology remains in its infancy (Garber, 1996). Of course, mandating LTC coverage mitigates the problem of adverse selection in the purchase of the insurance, but it does not help in terms of service utilization. Asymmetric information remains a concern regarding who needs the benefits: it is expensive and difficult to assess each person's case individually. There is some interesting recent research finding no positive correlation between LTC insurance purchase and the probability of entering a nursing home; indeed, Finkelstein and McGarry (2003) find that those who purchased LTC insurance in the US were more cautious and less likely to go into a nursing home, than those without coverage. For this reason, their research suggests that LTC insurance prices may not be unduly influenced by actuarially unfair selection, which eases the policy concerns about market failure.

There is increasing interest in developing approaches to measure the quality of care given in 
nursing homes and other LTC institutions. Carpenter et al. (2001) discussed five indicators for evaluating quality in the US context: falls by patients per month, the presence of pressure ulcers, fecal incontinence, restraint use, and social interaction with others. They reported that Japan had very low rates of pressure ulcers, while US homes had very good rates of social interaction but also high rates of falls and restraints. These authors proposed that all nursing homes be encouraged to gather data on these and other performance measures, and that insurers link outcomes to reimbursement patterns.

Further information on the quality differentials between for-profit versus public sector and nonprofit providers in the home-care marketplace in Japan is provided by Shimizutani and Suzuki (2002). That study reported that for-profit firms appear to have less experienced and trained staff, but the differences could be explained by the age of the business. Not surprisingly, younger firms had somewhat less experienced staff, but they also proved to have better information processing systems, better handling of accidents and emergencies, and better hygiene practices. Controlling on service quality, they reported that public providers cost slightly less, but newer firms were more efficient than older providers. These findings therefore confirm that competition contributes to improving the quality and efficiency of the market for at-home LTC services.

There may also be other reasons for why insurers have moved slowly into the LTC marketplace in the developed world. One issue is that there is inevitably substantial and fundamental uncertainty regarding the future paths of diseases, medical breakthroughs, and technological advances. Each of these could dramatically change future life expectancies, life years in frail condition, and consequent LTC costs. Also, the existence of LTC insurance may induce moral hazard: that is families may find it easier to "unload" their relatives to nursing homes, (recall the concept of “social hospitalization” mentioned above). Both factors help explain why private LTC policies in the US have had daily and lifetime (and sometimes financial) caps on coverage offered. In the past, many private policies did not guarantee renewability either, though this may be changing of late. And researchers have noted that private LTC policies are often not price indexed, meaning that the consumer remains at risk for out-of-pocket expenses over the long term. Perhaps most importantly, private policies have tended to be silent regarding what they will pay if the 
government were to dramatically change its policies regarding medical care coverage, out of pocket requirements, spend-down policies, and other related support. Such uncertainty on the consumer's part regarding the ultimate value of the private insurance surely serves to depress demand, and also depress offerings on the supply side.

In the Japanese context, some have talked about expanding the market for privately-financed medical care but several obstacles currently appear to impede expansion. Balance-billing by providers is currently not permitted, nor are investor-owned hospitals (Ikegami, 2003). Further, the government currently limits private insurance benefits to the provision of at-home care. Until private firms are permitted to operate nursing homes for the elderly, it is unlikely that market answers to the LTC challenge will be successful (Go, 2003). At-home care services are not thus restricted, but public funding or tax subsidies are not allowed to finance them. For this reason, private firms are at a substantial disadvantage vis a vis government-run operations.

Prior to the introduction of the public LTC program, private LTC insurance was not very widely sold in Japan. A key problem facing private insurers was adverse selection, due to the difficulty of measuring peoples' true health status. Now that the public LTC program has taken on the role of determining care needs and implied care levels required, this may make it easier for private insurers to predict and price risks.

Thus far, the niche for private LTC insurance in Japan has been mainly complementary to the public LTC program. One source of demand is for care if required before age 65, since the public program focuses on the elderly. Another possible source of demand would be for gap cover to meet the co-pays required by the public program - namely, the $10 \%$ of the service costs that the consumer must bear under the program.

There are signs that interest in private LTC is growing in Japan. For instance, the share of those with LTC insurance contracts in 2003 was $16 \%$ of those who purchased life insurance, more than a doubling of the rate only three years before (7\%; Japan Institute of Life Insurance, 2003). Providers of private LTC currently include private life insurance companies (e.g. Nippon Life Insurance Company); 
private property and casualty insurance companies; the National Mutual Insurance Federation of Agricultural Cooperatives (Zenkyoren); and the Postal Life Insurance Service of the Japan Postal system. As a rule, the insurance policies stipulated rather severe thresholds for disability, such as the condition of being bed-ridden or diagnosed as demented for more than a six-month period. For instance, a consumer who becomes bedridden for over six months after age 50 may receive $¥ 1.8$ million for ten years, under a policy offered by Sumitomo Life Insurance Company. Recently, however, there has been product innovation in this market, expanding the definition of the conditions required to receive benefits. For example, a policy sold by Sumitomo Life Insurance Company provides an income benefit if care is required for at least 30 days; another provider, American Family Insurance Company, pays benefits to consumers who are certified by the government as entitled to Care Level 1 or 2 .

\section{Potential Policy Responses}

When thinking about potential policy responses to challenges in the Japanese LTC environment, it is useful to remember that government providers in other countries have often underestimated the demand for subsidized care when launching a new system. For instance, Pratt (1999) notes that when the US government established public support for LTC under the Medicare and Medicaid programs, it assumed that then-current utilization rates would continue, but demand proved to be far greater than anticipated. If rationing continues to be a problem, either the government will have to raise mandatory premiums or other taxes to pay for enhanced benefits, or the market for private LTC insurance will have to be opened up.

When the publicly-provided elderly insurance program was introduced in 2000, the medical care system was also reformed to curtail the extent of social hospitalization, a major cause of rationing and increasing medical costs. That reform reduced officially-set prices for hospitalization applied to a "specific patient”, defined as an elderly person who remained in the same medical institution more than 90 days (except for several specific diseases). ${ }^{17}$ This decreased reward for medical institutions motivated them to discharge elderly patients after 90 days of care. According to the Survey on Patients by JMHLW, the

\footnotetext{
${ }^{17}$ For example, a typical rate for hospitalization for an elderly is 1,107 unit (1unit=10 yen) per day but it decreased to 928 units and this amount also included basic treatment (inspection, drug use, injection etc).
} 
average number of days in hospitals and clinics for the elderly age 65+ was 58.9 days in 1998, but this diminished to 53 days in 2002 (60.9 days in 1999, and 55.1 days for hospitals only). Average hospitalization days fell for all ages from 39.3 (1998) to 37.9 (2002) (or 41.8 to 40.1 for hospitals only), the decrease was larger for the elderly.

Yet we cannot conclude that those new policies completely erased “social hospitalization” and eliminated rationing. One reason is that the downward trend in average hospitalization days for the elderly started during the 1980s, prior to the new policies. Another is that after 90 days some hospitals are alleged to engage in a form of "musical chairs," discharging one set of patients but admitting a different groups' clients in order to reset the 90-day clock. To this end, some have proposed the development of private LTC insurance policies sold through benefit plans offered by employers. In the past, US employers have exhibited little interest in subsidizing this form of insurance directly (Weiner et al., 1994), but the 1996 Health Insurance Portability and Accountability Act (HIPAA) allows employer-paid premiums to be excluded from workers' salaries for tax purposes, and benefits are nontaxable up to a limit of actual LTC expenses (Rappaport and Stanger, 1997). Additionally, US legislators have recently introduced bills to make LTC insurance premiums tax deductible to employees who purchase the private insurance via an employer-based flexible benefits or "cafeteria” plan. These are plans where workers are granted by their firms a fixed dollar amount which then they can allocate across a range of benefit offerings. In addition, the proposed bill would grant a tax credit of \$3,000 per year to families who provide LTC services to relatives. Both provisions have an estimated revenue cost to the government of \$30B over the next decade (Rovner, 2003). Whether that or another legislative initiative will pass is unclear, but it does seem that tax subsidies for LTC purchase are likely in the future.

Another approach that would use the workplace as a nexus for LTC provision would be to permit workers to use their mandatory LTC premiums to purchase private coverage, perhaps of a catastrophic-only sort. Contracting out in this fashion would give workers the responsibility of shopping around for LTC coverage, and it would also offer the advantage of lower costs and more competitive products for those of working age. This approach would also be consistent with the national policy objective of enhancing 
opportunities for female labor supply (Shimizutani, Suzuki, and Noguchi, 2004). On the other hand, to the extent that the current government program is simply a pay-as-you-go tax-and-transfer system, rather than an insurance program with actuarially-fair premiums and reserves, allowing some workers to contract out would likely exacerbate financing problems for the portion of the program supporting the elderly.

One concern with tax incentives for LTC care is that they might be insufficient to induce low-wage workers to purchase enough LTC coverage. Nevertheless, rising costs of government financed-care have prompted a move to private market provision of care in several countries, including the UK, Germany, Australia, and Sweden (Go, 2003). Though not-for-profit providers have traditionally dominated the market in Europe, LTC services are increasingly being provided by for-profit companies in the US and the UK.

A proposal receiving attention in many aging nations is to combine private LTC insurance with annuity products, which would potentially boost the market for both annuities and LTC cover. For instance, Spillman et al. (2001) and Murtaugh et al. (2001) propose an arrangement whereby a privately-sold life annuity product provides monthly payments that rise in the event that the insured party is certified as chronically and permanently disabled. For example, at retirement the annuity would begin paying $\$ 1,000 /$ month to the purchaser, but the cash payment would rise to $\$ 2,000 /$ mo if the participant was certified to need help with at least two ADLs (after a one-month waiting period), or if he were certified as having been cognitively impaired (for a minimum of 90 days). Other formulas could also be envisioned, of course. The proposal's appeal is that the two-tiered coverage -longevity protection due to the annuity, plus a step-up in cash benefits if disabled - may attract more buyers than would a simple life annuity or a simple LTC scheme. This would be expected to reduce the potential for adverse selection which otherwise has been seen as a major obstacle to annuity sales (Brown et al. 1999). Indeed, in the Japanese context, the Postal Saving System has a product of this sort on offer.

Providing the elderly with cash benefits instead of service benefits does give consumers a wider range of choices than the current service-based approach embodies. Yet it is interesting that in Japan, a voucher system or cash benefit was discussed and rejected in the late 1990s (Campbell and Ikegami, 2000). 
The major concerns were that providing cash might not afford needed relief to (mainly female) caregivers of the elderly, and also that offering cash might induce substantial increases in demand. Further, it appears that policymakers felt that shortages of formal care would best be met by provision of new service facilities. To this day, these facilities are still constructed with heavy capital subsidies from the public sector. Consequently, government policy still tends to discourage innovative privately-sold forms of LTC including assisted living, group homes, and graduated retirement care communities. LTC service benefits have also been limited to room and board coverage and have not been integrated with medical care benefits. This limits providers' incentives to manage residential, medical, and rehabilitative needs in a coherent and systematic fashion. Finally, problems may arise if people are discharged from LTC institutions due to reaching their charge limits while still in need of medical care.

It should be noted that there are advantages to the Japanese system of providing service instead of cash benefits, with means-tested premiums, co-pays, and out-of-pocket limits. One is that consumers are actually quite well protected against catastrophic LTC costs. This is in sharp contrast with private LTC insurance packages on offer in the US, which pay the LTC consumer a specified daily dollar benefit over a specified and limited number of years. The US format has the advantage of limiting insurers' liability, but it does mean that elderly patients may be left without coverage after exhausting the privately-financed benefit. This in turn would lead them to have to draw down other assets, sell their houses, and/or rely on Medicaid, the public plan for the indigent.

A different approach to LTC would rely on dependents, particularly children, to bear a larger share of LTC costs among the elderly. A tactic adopted in New Zealand and China is to mandate that offspring of working age must support their own needy parents. This could be combined with an insurance-based approach such as in Singapore, where private insurance coverage could be purchased by working-age children for their elderly families (Lee 2003). A different method of risk-pooling would be to require all workers, including those under the age of 40, to pay premiums for mandatory LTC insurance purchase, as suggested for Japan by Campbell and Ikegami (2000). The idea here is that the risk pool is relatively homogeneous early in life, while more and more people at older ages would fail underwriting criteria if they 
waited to purchase LTC insurance later. For example, in US data, 89\% of people age 40-44 could meet LTC underwriting criteria, but only 68\% of those age 70-74 are healthy enough to meet the screens (Merlis, 2003).

An indirect way to have families "pay" for LTC would be to facilitate the development of reverse mortgages (RMs) for the elderly. These products can permit an elderly homeowner to borrow against the value of his house to enhance his current consumption, perhaps by retrofitting the home to make it suitable for elderly living. The lender receives no interest or principal payments until the homeowner dies or vacates his home, at which time the residence is sold and the proceeds used to repay his loan. RMs may be attractive to the elderly because they are permitted to remain in their homes until death, and in exchange, they benefit from additional retirement income. An important feature of a RM loan is that it is "non-recourse," so that the borrower's other assets cannot be accessed by the lender to cover loan repayment (Mitchell and Piggott, 2003). In this event, turning home equity into liquid form enhances a retiree's ability to obtain LTC services while remaining out of the hospital. This is particularly key in the Japanese context since elderly Japanese appear to have housing equity that is some 50 percent larger than their US counterparts. Of course, taking an RM does have the effect of shrinking retirees’ estates. ${ }^{18}$

\section{Conclusions and Directions for Future Research}

Our review of long-term care in the Japanese context has drawn out several interesting aspects of the system that was launched in 2000. For historical reasons, health care continues to be paid for and delivered by the separate national health insurance system. Thus the Japanese approach to LTC has emphasized the provision of at-home (nonmedical) services, as well as room and board for those requiring institutionalization. The Japanese LTC system is a rather complex tax-and-transfer scheme, supported by mandatory but means-tested premiums levied on workers and retirees by local governments, as well as general tax revenue from central and local governments. Benefit eligibility is determined by local boards appointed by municipalities, but fees for benefits are set at the national level. For-profit competition is permitted in the at-home care arena, but in the medical and institutional care arenas only non-profits and 
government providers are allowed.

Our analysis has identified several upcoming challenges and clouds on the horizon. The best available projections suggest that LTC costs in Japan will grow substantially in the future, a fact that will be a central focus of the 2005 LTC system review. Clearly the aging population will drive up demand for LTC, but our analysis also suggests that rising incomes and bed capacity will drive demand up and further boost costs. The current system does integrate deductibles, copays, and caps, all of which do curtail demand and hence expenditures somewhat, but continuing substantial subsidies for LTC will surely boost future utilization rates beyond simple population projections. As a result, rationing has already emerged and it will likely become even more widespread, which in turn is likely to contribute to political stress as the population ages. Cost pressures and evasion problems will potentially also require extending the mandatory premiums to workers under age 40 who are not currently included in the system.

Another issue we have raised is the fact that the centralized-but-decentralized system tends to do little to smooth regional disparities in the concentration of elderly and frail elderly. Some cross-subsidization does occur by means of the central government, but it is unclear how policies will respond to future regional and national LTC shortages. Additional research is required to help separate the roles of demand and supply for LTC entitlement and utilization patterns, though our analysis indicates (a) that demand is sensitive to income and prices; and (b) the municipalities may not be the most efficient decision locus to handle the entitlement process, benefit determination, provision of care, and financing, particularly given the efforts to standardize eligibility criteria.

While the market for privately-sold LTC products is small, as yet, it does appear that demand has grown over the last three years. Greater private provision of LTC insurance might be an appealing outcome to the extent that the elderly have sufficient income/assets to purchase the coverage. Of course it does depend on LTC consumers and their relatives becoming sufficiently well-informed about quality and price of services to make the market function well. Development of national LTC quality standards for institutional and at-home care services would facilitate consumer shopping for private LTC coverage. Less

\footnotetext{
${ }^{18}$ The UK has high buy-in prices for nursing home care for owner-occupiers.
} 
clear is the ability of private insurers to structure LTC policies that can both attract consumers and also mitigate adverse selection. One possibility might be to sell employer-based policies to workers at younger ages. Plan design features intended to limit moral hazard could logically draw on some already embodied in the current public LTC system, including co-insurance, deductibles, and the determination of need by a third party which is relatively free of conflicts-of-interest. In addition, privately provided LTC cash benefits could be an attractive alternative to the current indemnity approach used by the government, which provides services rather than cash. Last but not least, there may be a role for reverse mortgages in Japan, as a means of financing services and provide care for an increasingly long-lived and numerous elderly population. 


\section{Bibliography}

All-Japan Federation of National Health Insurance Organizations (AJFNHIO). 2003. http://www.kokuho.or.jp/

American Health Care Association (ACHA). "AHCA Announces National Nursing Home Week Theme and Dates.” Dec 9, 2003. http://www.ahca.org/news/nr031209a.htm

Asahi Shimbun. “233,000 Seniors in Limbo on Nurse Care.” Tokyo, Feb. 6, 2003. http://www.asahi.com/english/politics/K2003020600237.html

Brown, Jeffrey, Olivia S. Mitchell, James Poterba, and Mark Warshawsky. The Role of Annuity Markets in Financing Retirement. MIT Press, 2001.

Campbell, John C. and Naoki Ikegami. The Art of Balance in Health Policy: Maintaining Japan's Low-Cost Egalitarian System. Cambridge: Cambridge University Press, 1998.

Campbell, John C. and Naoki Ikegami. “Long-term Care Insurance Comes to Japan.” Health Affairs, 19(3): 26-39.

Carpenter, Ian, John Hirdes, and Naoki Ikegami. “Long-term Care: A Complex Challenge.” OECD Observer, December 2001.

http://www.oecdobserver.org/news/printpage.php/aid/558/long_term_care:a_complex_challenge. html

Doerpinghaus, Helen and Sandra Gustavson. “Long-Term Care Insurance Purchase Patterns.” Risk Management and Insurance Review. 5(1) 2002:31-43.

Doteuchi, Akio. "Building a Welfare Infrastructure to Support Independent Living for the Aging Population.” In Aged-ing In Japan. Research Booklet, NLI Research Institute, AGHE Annual Conference, St. Petersburg. 2003. Tokyo: NLI Research Institute: 221-229.

Finkelstein, Amy and Kathleen McGarry. "Private Information and its Effect on Market Equilibrium: New Evidence from Long-Term Care Insurance.” NBER Working Paper, Sept. 2003.

Fries, James. “Aging, Natural Death, and the Compression of Morbidity.” New England Journal of Medicine. July 17, 1980. 303(3):130-135. http://content.nejm.org/cgi/content/abstract/303/3/130

Garber, Alan M. “To Comfort Always: The Prospects of Expanded Social Responsibility for Long-Term Care.” In Individual and Social Responsibility. Ed. V. R. Fuchs. Chicago: NBER and University of Chicago Press, 1996: 143-174.

Garber, Alan and Thomas MaCurdy. "Forecasting Nursing Home Utilization of Elderly Americans.” In Studies in the Economics of Aging. Ed. D. Wise. Chicago: Univ. of Chicago Press, 1994.

Garber, Alan M. and Thomas MaCurdy. "Predicting Nursing Home Utilization Among the High-Risk Elderly.” In David A. Wise, ed. Issues in the Economics of Aging. 1990. Chicago: Univ. of Chicago Press: 173-200.

Go, Kazuhisa. “The Introduction of Market Mechanisms for Long-Term Care Services.” In Aged-ing In Japan. Research Booklet, NLI Research Institute, AGHE Annual Conference, St. Petersburg. 2003. Tokyo: NLI Research Institute: 231-239.

Headen, Alvin E. "Economic Disability and Health Determinants of the Hazard of Nursing Home Entry.” Journal of Human Resources 1993. 28 (1): 88-110.

Ikegami, Naoki. “Japan’s Health Care System: Containing Costs in a Stagnant Economy.” Presentation for The Wharton School, October 2003.

Ikegami, Naoki. “Japan’s Long-Term Care Insurance Program: Making LTC an Entitlement.” Presentation for The Wharton School, no date. 
Ikegami, Naoki and John Campbell, eds. Containing Health Care Costs in Japan. Ann Arbor: Univ. of Michigan Press, 1996.

Ikegami, Naoki and John Campbell. "Health Care Reform in Japan: The Virtues of Muddling Through.” Health Affairs, May June 1999: 305-314.

Ikegami, Naoki and John Campbell. “Long-Term Care Insurance Comes To Japan.” Health Affairs 19(3), 2000:26-39.

Ikegami, Naoki and Takeshi Yamada. "Comparison of Long-Term Care for the Elderly between Japan and the United States. In Ikegami, Naoki and John Campbell, eds. Containing Health Care Costs in Japan. Ann Arbor: Univ. of Michigan Press, 1996: 155-171.

Iwaisako, Tokyo, Olivia S. Mitchell, and John Piggott. "Strategic Asset Allocation in Japan: An Empirical Evaluation.” Presented at the 2004 ESRI International Conference, 2004. Tokyo.

Japan Institute of Life Insurance (JILI). 2003. “Survey on Life Insurance in FY 2003.”(in Japanese). Tokyo. http://www.jili.or.jp/cgi-local/ldall.cgi?ldpage=../pdf/h15zenkoku.pdf

Japan Ministry of Health, Labor and Welfare. (JMHLW). 1993, 1996,1998. "Basic Survey on People's Life.” (Kokumin Seikatsu Kiso Chousa, in Japanese). Tokyo. 1993: not on internet.

1999: http://www1.mhlw.go.jp/toukei/h10-ktyosa/index_8.html

1996: http://www1.mhlw.go.jp/toukei/ksk/index.html

Japan Ministry of Health, Labor and Welfare. (JMHLW), 2003(a). "Elderly Care in 2015: Establishing Elderly Care to Support Dignity of the Elderly.” (in Japanese) Tokyo.

http://www.mhlw.go.jp/topics/kaigo/kentou/15kourei/index.html

Japan Ministry of Health, Labor and Welfare. (JMHLW), 2003(b). "Standards on calculation of services costs approved at-home care services" (Sitei Kyotaku Service ni Yousuru Hiyou no Gaku no Santei ni kansuru Kijyun)

Japan Ministry of Health, Labor and Welfare. (JMHLW), 2003(c) "Standards on calculation of services costs approved institutional care services" (Sitei Shisetsu Service tou ni Yousuru Hiyou no Gaku no Santei ni kansuru Kijyun)

Japan Ministry of Health, Labor and Welfare. (JMHLW). 2002. "Long-term Care Insurance in Japan.” Tokyo. http://www.mhlw.go.jp/english/topics/elderly/care/index.html

Japan Ministry of Health, Labor and Welfare. (JMHLW). Various years. "Survey on Care Service Providers.” (Kaigo Service Shisetsu Jigyousho Chousa, in Japanese.) Tokyo. http://www.mhlw.go.jp/toukei/saikin/hw/kaigo/service00/index.html

Japan Ministry of Public Management, Home Affairs and Posts and Telecommunications (JMPMHAPT). Statistics Bureau. 2003. “Land Area.” Tokyo. http://www.stat.go.jp/english/data/nenkan/1431-01.

Japan Ministry of Public Management, Home Affairs and Posts and Telecommunications. (JMPMHAPT) Statistics Bureau. 2003. "Population Data.” Tokyo. http://www.stat.go.jp/english/data/jinsui/index.htm

Japan National Institute of Population and Social Security Research. (JNIPSSR). 2003. "Population Projections for Japan: 2001-2050.” http://www.ipss.go.jp/index-e.html

Kampo. "Detailed Explanations of Individual Products/Basic Contracts.” Tokyo. http://www.kampo.japanpost.jp/osirase/report/disclo_e/3-2-1.html

Kishida, Hiroshi. “A Market Projection for Long-Term Care in Japan.” NLI Research Institute Bulletin No. 116, 1998. Reprinted in Aged-ing In Japan. Research Booklet, NLI Research Institute, AGHE Annual Conference, St. Petersburg. 2003. Tokyo: NLI Research Institute: 241-237.

Kishida, Hiroshi. “Housing for Elderly Persons.” NLI Research Report May 2002. Reprinted in Aged-ing In Japan. Research Booklet, NLI Research Institute, AGHE Annual Conference, St. Petersburg. 2003. 
Tokyo: NLI Research Institute: 269-277.

Komamura, Kohei and Atsuhiro Yamada. "Who Bears the Burden of Social Insurance? Evidence from the Japanese Health and Long-Term Care Insurance Data.” NBER WP 10339,March 2004.

Lakdawalla, Daris, and Tomas Philipson. "The Rise in Old-Age Longevity and the Market for Long-Term Care.” American Economic Review. March 2002. 295-306.

Lee, Karen. “LTC Insurance Providers Try To Come Up With New Twists.” Employee Benefit News. 2003. December. www.benefitnews.com/supplemental/detail.cfm?id=5385.

Lubitz, James, Liming Cai, Ellen Kramarow, and Harold Lentzer. "Health, Life Expectancy, and Health Care Spending Among the Elderly.” New England Journal of Medicine. 349:11, September 11, 2003: 1048-1055.

McCall, Nelda, Ed. Who Will Pay for Long Term Care? Academy for Health Services Research and Health Policy. Chicago: Health Administration Press, 2001.

McCall, Nelda and Jodi Korb. "What Have We Learned from the Partnership for Long-term Care?” In Who Will Pay for Long Term Care? Ed. Nelda McCall. Academy for Health Services Research and Health Policy. Chicago: Health Administration Press, 2001: 149-184.

Merlis, Mark. “Private Long-Term Care Insurance: Who Should Buy It and What Should They Buy?” Report to the Kaiser Family Foundation. Menlo Park, CA: March 2003.

Metlife. The MetLife Market Survey of Nursing Home and Home Care Costs. Mature Market Institute Report. New York: MetLife, 2003.

Mitchell, Olivia S. and John Piggott. "Housing Equity and Senior Security.” Presented at the 2003 ESRI International Conference. 2003. Tokyo, Japan.

Mitchell, Olivia S. \& John Piggott. “Unlocking Home Equity in Japan,” Journal of the Japanese and International Economies. Dec. 2004: 1-24.

Murtaugh, Christopher, Brenda Spillman, and Mark Warshawsky, "In Sickness and In Health: An Annuity Approach to Financing Long-Term Care and Retirement.” Journal of Risk and Insurance. 68(2): 2001: 225-254.

National Center for Health Statistics. “US Nursing Homes Profiled in New Report”. June 19, 2002. http://www.cdc.gov/nchs/releases/00facts/nurshome.htm

Noguchi, Haruko and Satoshi Shimizutani. "The Determinants of Nursing Home Exit and the Price Elasticity of Institutional Care: Evidence from Japanese Micro-Level Data..” ESRI Discussion Paper 24, Tokyo, December 2002.

Noguchi, Haruko and Satoshi Shimizutani. "Earnings and Quality Differentials in For-Profit Long-Term Care: Evidence from Japan’s Long-Term Care Market.” ESRI Discussion Paper 17, Tokyo, December 2002.

Noguchi, Haruko and Satoshi Shimizutani. “A Long-term Projection of Demand for At-home Care Services in Japan” ESRI Discussion Paper 60, Tokyo, 2003.

Noguchi, Haruko and Satoshi Shimizutani. "Is Non-profit Status a Signal of Better Quality? Micro-level Evidence from Japan's At-home Care Industry" ESRI Discussion Paper 80, Tokyo, November 2003.

Norton, Edward C. “Long Term Care”. Handbook of Health Economics. Vol. 1. Eds A.J. Culyer and J.P. Newhouse. Amsterdam: Elsevier, 2000.

Ohkusa, Yasushi. "An Empirical Analysis of Actual Demand for Care Covered by the Long-term Care Insurance for Elderly: Estimation for Classified Household Types.” Quarterly of Social Security Research. (in Japanese) 38(1). 2002a: 67-73.

Ohkusa, Yasushi. “Price Elasticity of Actual Demand of Care for the Elderly.” Quarterly of Social Security 
Research. (in Japanese) 38(3). 2002(b): 239-244.

Pauly, Mark. “The Rational Nonpurchase of Long-Term Care Insurance.” Journal of Political Economy. 1990. 98(1): 153-168.

Powell, Alwyn. Actuarial Data Requirements for Continuing Care Retirement Communities. 1998. http://www.avpowell.com/docs/Actuarial\%20Data\%20Requirements\%20for\%20CCRCs,\%20199 $\underline{\text { 8.pdf }}$

Pratt, John R. Long-Term Care: Managing Across the Continuum. Gaithersburg, MD: Aspen Publications, 1999.

Rappaport, Anna and Janice Stanger. "Postemployment Benefits: Financial Considerations in the Development of a Group Long-term Care Insurance Program.” Compensation and Benefits Management. Winter 1997:62-68.

Robinson, Jim. “A Long-Term Care Status Transition Model.” The Old-Age Crisis: Actuarial Opportunities. The 1996 Bowles Symposium. Georgia State University, Dept. of Actuarial Science: 1996.

Rovner, Judith. “US Bill Would Encourage Long-Term Care Insurance.” Reuters, 5/15/03. www.reutershealth.com/archive/2003/05/15/eline/links/20030515elin015.html

Shimizutani, Satoshi and Noguchi, Haruko (2004) Kaigo Hoiku Service Sizyou no Keizai Bunseki (An Economic Analysis on Japanese Long-term and Child Care Markets), Toyo Keizai Shimpo Sha, Tokyo.

Shimizutani, Satoshi and Wataru Suzuki. "The Quality and Efficiency of At-Home Long-Term Care in Japan: Evidence from Micro-Level Data.” ESRI Discussion Paper 18, Tokyo, December 2002.

Shimizutani, Satoshi, Wataru Suzuki, and Haruko Noguchi. "Outsourcing At-Home Elderly Care and Female Labor Supply: Micro-Level Evidence from Japan’s Unique Experience.” ESRI Discussion Paper Series No. 93, Tokyo: ESRI, April 2004.

Spillman, Brenda, Christopher Murtaugh, and Mark Warshawsky, "Integration of the Life Annuity and Long-Term Care Insurance: Theory, Evidence, Practice, and Policy.” In Innovations for Financing Retirement, Eds. Zvi Bodie, Brett Hammond, and Olivia Mitchell. Philadelphia: The University of Pennsylvania Press, 2001.

Stucki, Barbara. “Insurers.” In Who Will Pay for Long Term Care? Ed. Nelda McCall. Academy for Health Services Research and Health Policy. Chicago: Health Administration Press, 2001: 97-112.

Suzuki, Wataru and Yasushi Ohkusa. "Empirical Analysis of the Market of Social Insurance for Elderly Care.” Quarterly of Social Security Research. (in Japanese) 36(3). 2000: 338-352.

US Central Intelligence Agency (CIA). World Factbook. US Government, 2003. http://www.cia.gov/cia/publications/factbook/geos/us.html\#Intro

Wiener, Joshua, Laurel Hixon Illston, and Raymond J. Hanley. Sharing the Burden. Washington, D.C.: Brookings, 1994.

Yashiro, Naohiro, Takashi Oshio, Yasuhiro Terasaki and Masayuki Miyamoto. “ An Economic Analysis on Long-term Care Insurance.” Institute of Economics, Economic Planning Agency. Tokyo, 1996. 
Figure 1. Dependency Ratios by Regio: Japanese Elderly and Entitled to LTC

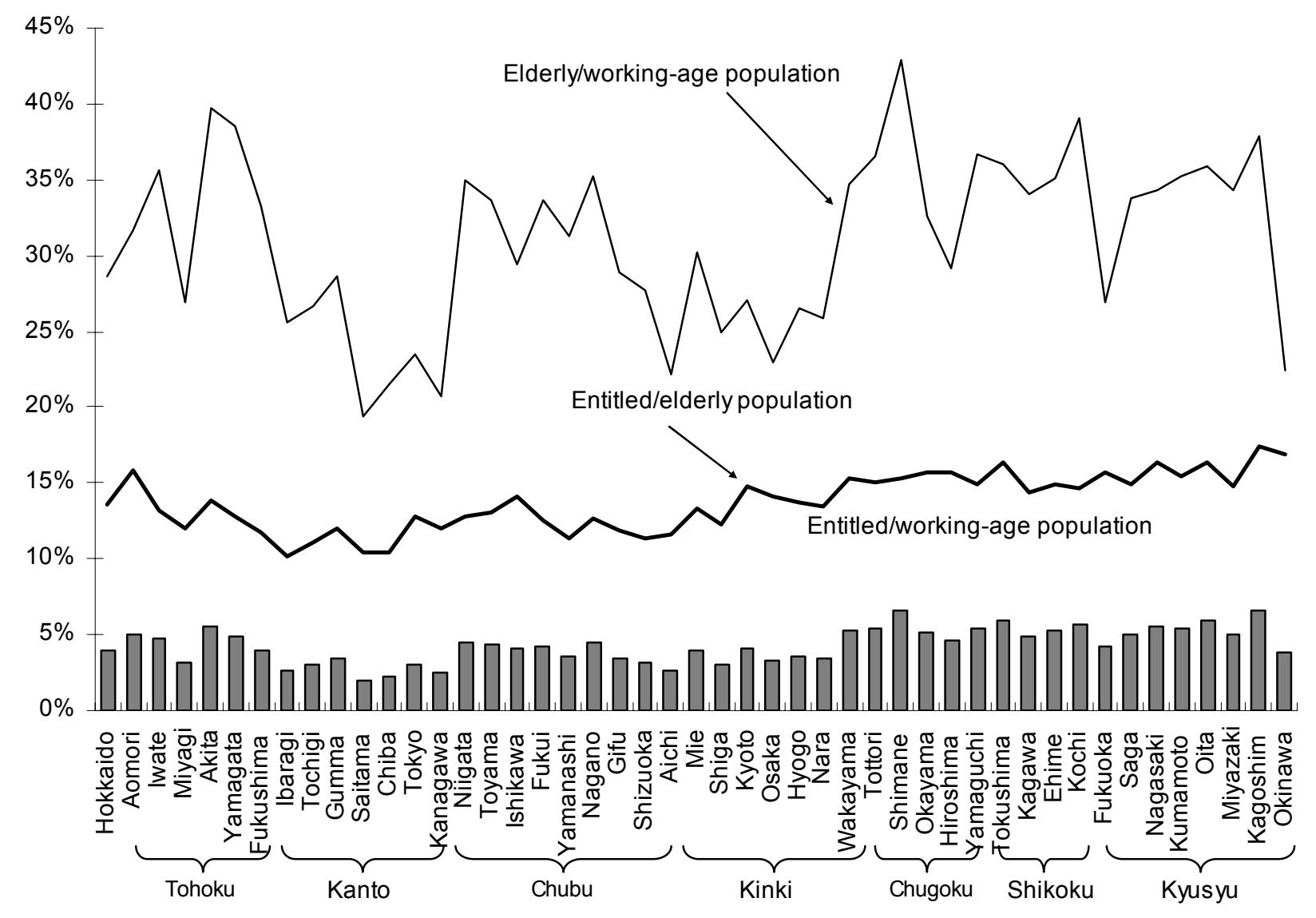

Source: Authors' calculations using data provided by Japan’s Ministry of Health, Labor and Welfare; National Health Insurance Association of Japan; and Statistics Bureau of Japan. 
Figure 2. Institutional Care Capacity by Region in Japan

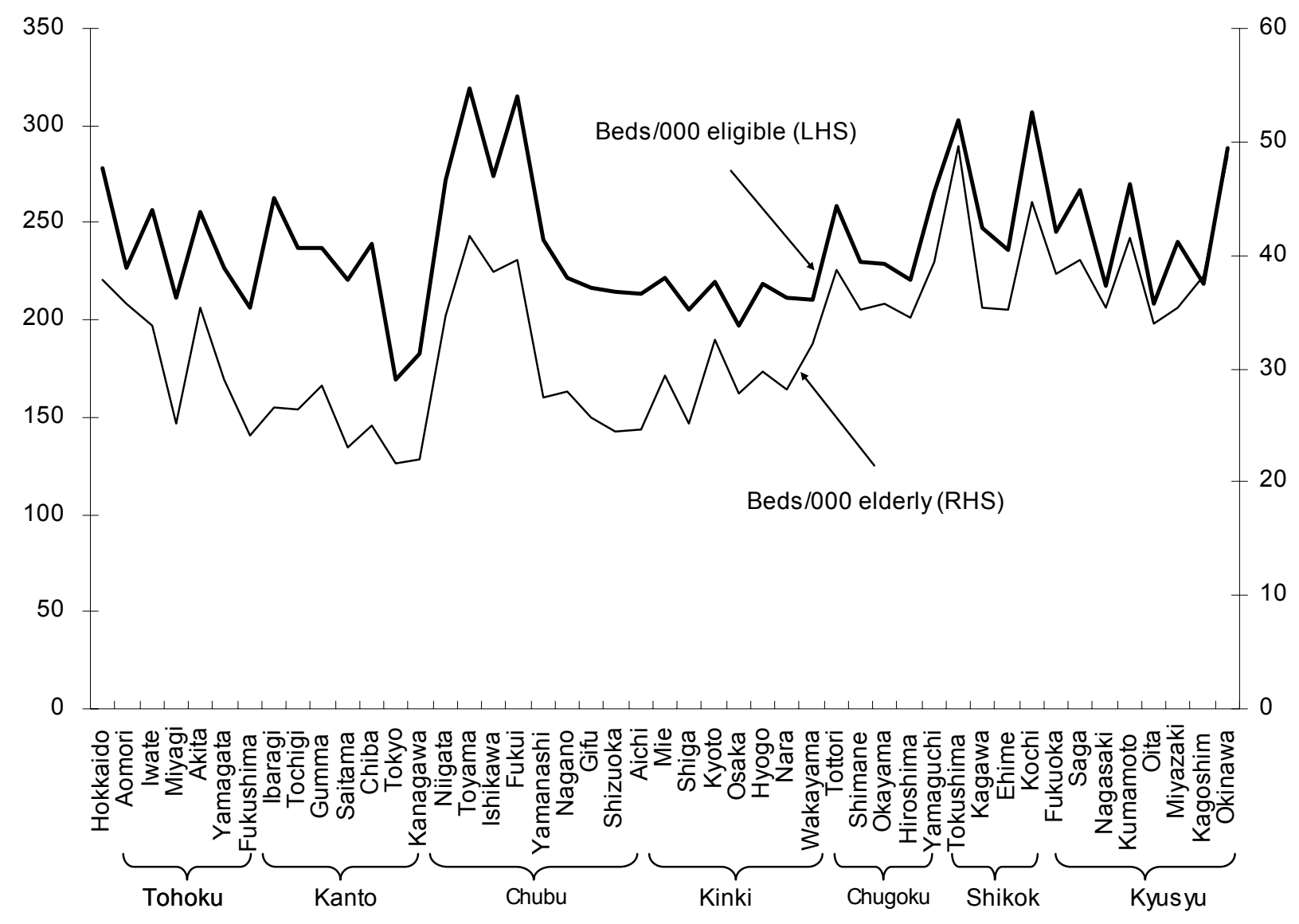

Source: Authors' calculations using data provided by Japan’s Ministry of Health, Labor and Welfare; National Health Insurance Association of Japan; and Statistics Bureau of Japan. 
Figure 3. Long-term Care Utilization Rates by Region in Japan

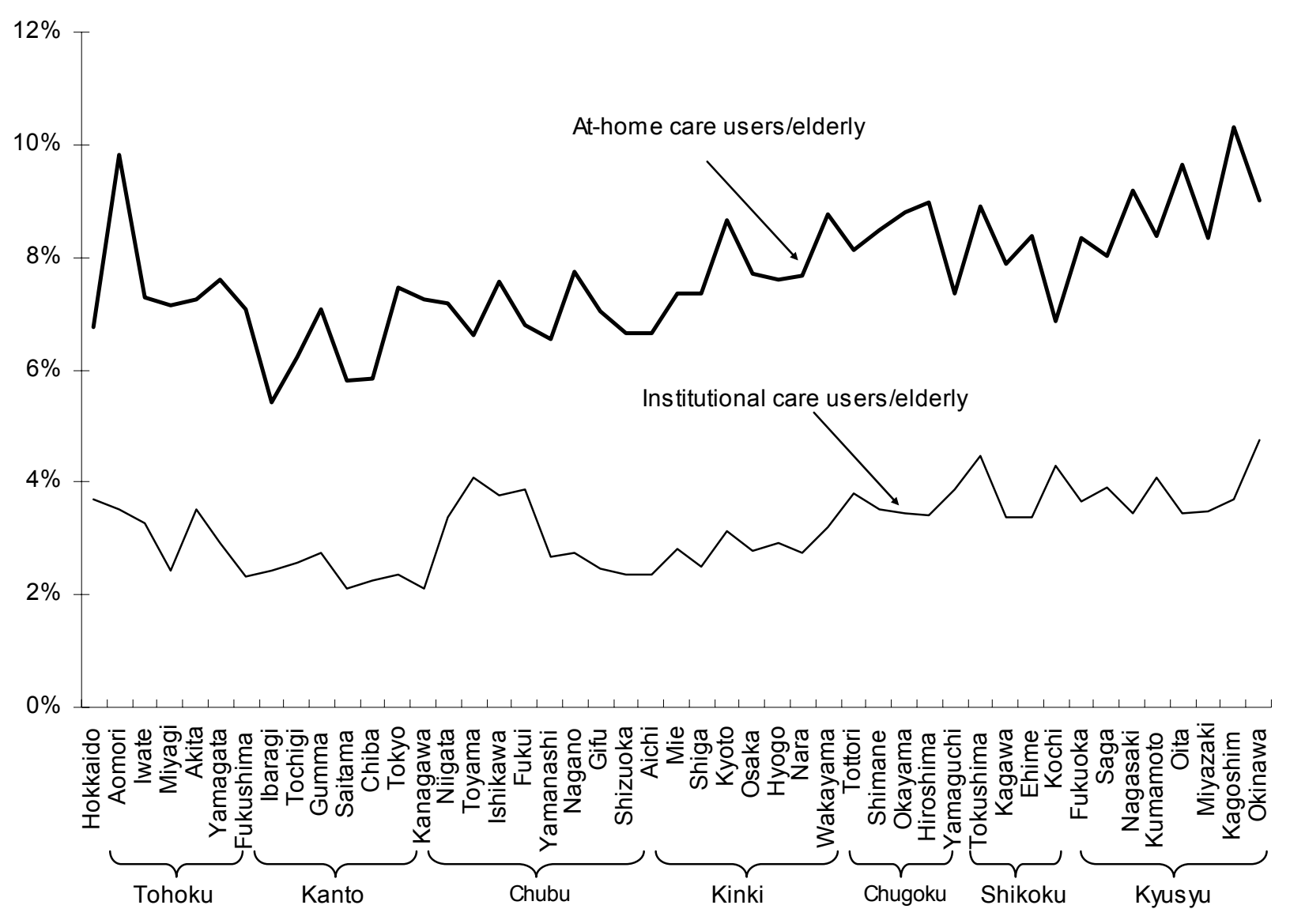

Source: Authors' calculations using data provided by Japan's Ministry of Health, Labor and Welfare; National Health Insurance Association of Japan; and Statistics Bureau of Japan. 
Figure 4. Long-term Care Fees by Region in Japan

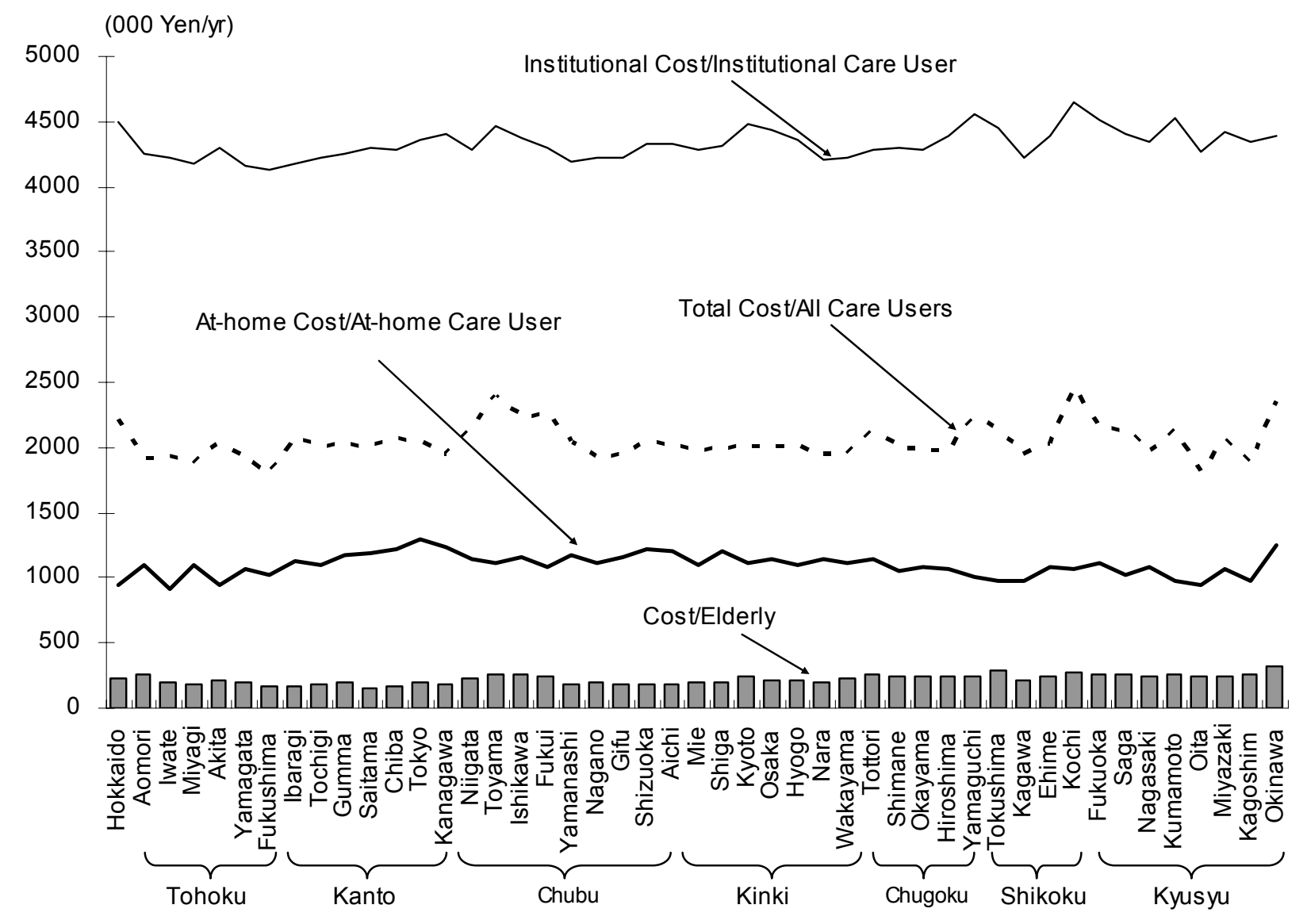

Source: Authors' calculations using data provided by Japan’s Ministry of Health, Labor and Welfare; National Health Insurance Association of Japan; and Statistics Bureau of Japan. 
Table 1: Unit Costs for LTC Services (2000 ¥) At-home Care

Home-help services

\begin{tabular}{|c|c|c|}
\hline Physical Assistance & $<30$ min & 231 \\
\hline & 0.5-1 hour & 402 \\
\hline & 1-1.5 hours & 584 \\
\hline & +30 min. & 83 \\
\hline Daily Life & $<30 \min$ & 208 \\
\hline & 0.5-1 hour & 291 \\
\hline & +30 min. & 83 \\
\hline Home-visit bathing & per time & 1250 \\
\hline $\begin{array}{l}\text { Home-visit } \\
\text { ehabilitation } \\
\text { Home-visit nursing }\end{array}$ & per day & 550 \\
\hline Provided by & $<30$ min. & 425 \\
\hline & 0.5-1 hour & 830 \\
\hline & 1-1.5 hours & 1198 \\
\hline Provided by & $<30$ min. & 343 \\
\hline & 0.5-1 hour & 550 \\
\hline & $1-1.5$ hours & 845 \\
\hline
\end{tabular}

Day services (operated jointly by institutions)

Support required $\quad 3-4$ hours

$4-6$ hours

$6-8$ hours

Care Levels 1 or 2 3-4 hours

$4-6$ hours

6-8 hours

Care Levels 3, 4 or $3-4$ hours

5

4-6 hours

6-8 hours

Day services (rehabilitation at LTC health services)

Support required 3-4 hours
Units

31

02

84

208

291

50

550

25

830

198

550

845

344

482

307

438

614

452

645

903

\section{Institutional Care}

LTC welfare institutions

Care level $1 \quad$ per 677

Care level 2 per $\quad 748$

Care level $3 \quad$ per 818

Care level $4 \quad$ per 889

Care level $5 \quad$ per 959

day

LTC health 819

institutions

Care level $1 \quad$ per 868

Care level $2 \quad$ per $\quad 921$

Care level 3 per 975

Care level $4 \quad$ per 1028

day

Care level $5 \quad$ per $\quad 830$

day

LTC medical institutions

Care level 1 per 820

$\begin{array}{lll} & \text { day } & \\ \text { Care level } 2 & \text { per } & 930\end{array}$

Care level 3 per 1168

Care level $4 \quad$ per 1269

day $\quad 1360$

Care level 5 per

day 


$\begin{array}{lll} & \text { 4-6 hours } & 344 \\ & \text { 6-8 hours } & 482 \\ \text { Care Levels 1 or 2 } & \text { 3-4 hours } & 307 \\ & 4-6 \text { hours } & 438 \\ & \text { 6-8 hours } & 614 \\ \text { Care Levels 3, 4 or } & \text { 3-4 hours } & 452 \\ 5 & & \\ & \text { 4-6 hours } & 645 \\ & \text { 6-8 hours } & 903\end{array}$

Short Stay (operated independently: nurses are 1/3 of staff)

$\begin{array}{llr}\text { Support required } & \text { per day } & 831 \\ \text { Care level 1 } & \text { per day } & 875 \\ \text { Care level 2 } & \text { per day } & 946 \\ \text { Care level 3 } & \text { per day } & 1016 \\ \text { Care level 4 } & \text { per day } & 1087 \\ \text { Care level 5 } & \text { per day } & 1157\end{array}$

Short Stay (operated jointly by institutions: nurses are $1 / 3$ of staff)

$\begin{array}{ll}\text { Support required } & 797\end{array}$

Care level $1 \quad$ per day 841

Care level 2 per day 912

Care level 3 per day 982

Care level $4 \quad$ per day 1053

Care level $5 \quad$ per day 1123 
Table 2. Projected LTC Costs in Japan (in trillion $2000 ¥$ )

\begin{tabular}{|c|c|c|c|c|c|}
\hline & & 1 & 2 & 3 & 4 \\
\hline 1 & Study Authors and Date & $\begin{array}{l}\text { JMHW } \\
(1996) \\
\end{array}$ & $\begin{array}{c}\text { Yashiro et.al } \\
(1996)\end{array}$ & $\begin{array}{c}\text { Noguchi \& Shimizutani } \\
(2003)\end{array}$ & $\begin{array}{r}\text { JMHLW } \\
.(2003) \\
\end{array}$ \\
\hline 2 & Projection Dates & $2000,2010,2025$ & $2000,2010,2025$ & $2010,2015,2025$ & $\begin{array}{c}\text { \# elderly with dementia: every } 5 \text { yrs to } 2045 \\
\text { Costs: } 2005,2015,2025\end{array}$ \\
\hline 3 & Coverage & \begin{tabular}{|c|} 
\# elderly \\
\# elderly requiring LTC \\
\# elderly bedridden \\
\# physically weak elderly \\
\# elderly with dementia
\end{tabular} & $\begin{array}{c}\text { \# elderly } \\
\text { \# elderly requiring LTC } \\
\text { \# elderly bedridden } \\
\text { \# physically weak elderly } \\
\text { \# elderly with dementia } \\
\text { Total Costs }\end{array}$ & $\begin{array}{l}\text { Costs of At-home Care } \\
\text { (i) Home visit and day care } \\
\text { (ii) Short stay }\end{array}$ & $\begin{array}{c}\text { \# elderly with dementia (rank 2-5 \& 3-5) } \\
\text { Total Evaluation Payments* }\end{array}$ \\
\hline 4 & Estimated Patient Pool & $\begin{array}{r}\text { \# eligible }=5.2 \mathrm{~m}(2025) \\
=16 \% \text { of the elderly }\end{array}$ & $\begin{array}{l}\text { \# eligible }=3.7 \mathrm{~m}(2010) \\
\text { \# eligible }=4.9 \mathrm{~m}(2025)\end{array}$ & & N.A. \\
\hline 5 & Estimated Cost per Patient & N.A. & & & N.A. \\
\hline 6 & Estimated Total Program Costs Projected & N.A. & $\begin{array}{l}\text { 2000: } ¥ 10.3 \mathrm{Tr} \\
2025: ¥ 33.2 \mathrm{Tr}\end{array}$ & $\begin{array}{l}\text { (i) Home visit and day care; (ii) Short stay } \\
2010 \text { : } ¥ 3.1 \operatorname{Tr} \text { (i) and } ¥ 0.3 \operatorname{Tr} \text { (ii) } \\
2015: ¥ 4.3 \operatorname{Tr} \text { (i) and } ¥ 0.4 \operatorname{Tr} \text {. (ii) } \\
2025: ¥ 4.8 \operatorname{Tr} \text { (i) and } ¥ 0.5 \operatorname{Tr} \text {. (ii) }\end{array}$ & 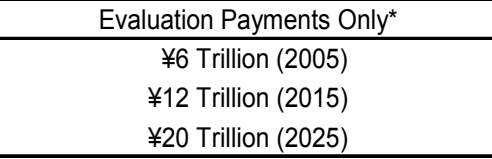 \\
\hline 7 & $\begin{array}{l}\text { Estimated Program Costs as } \\
\text { Share of National Income }\end{array}$ & N.A. & & & $\begin{array}{l}1.5 \%(2005) \\
2.5 \%(2015) \\
3.5 \%(2025) \\
\end{array}$ \\
\hline 8 & Additional Comments & Official projections & & & Quasi-official projections \\
\hline
\end{tabular}

Note: Evaluation Payments refer to payments made by the government, exclusive of the consumer's out of pocket and deductible amounts. 


\section{Table 2 (cont)}

B. Alternative LTC Cost Projections

1. Assumptions

a) The number of elderly in 2025: 34.7 million $\Delta$

b) The share of eligible out of total elderly: 5.6 million $(34.7$ million * $(5.2 / 32.4=16.0 \%))$

2. Projections

Case 1: Costs per eligible person in 2001-2003 of $¥ 1.6 \mathrm{M}$ assumed for 2025.

Total Cost $=5.6$ million $¥ ¥ 1.6$ Million (av. 2001-03) $=¥ 8.96$ Trillion.

Case 2-1: Adjusting only the number of users of at-home care

Costs per institutional care user remain unchanged from 2001-2003 (about $¥ 4.3$ million)

Costs per at-home care user remain unchanged from 2003 level (= $¥ 1.24$ million)

Share of institutional care users set at $20.0 \%$ (vs $23.2 \%$ in $2001,21.2 \%$ in 2002 , and $20.0 \%$ in FY2003).

Share of at-home care users increases by $1.5 \%$ annually to $74.1 \%$ in 2025 (was $55.1 \%$ in $2001,57.0 \%$ in 2002 and $57.6 \%$ in 20 C

Total Cost $=¥ 1.24$ million * 5.6 million * $0.741+¥ 4.31$ million $* 5.6$ million * $0.200=¥ 9.97$ trillion

Case 2-2 Adjusting the number of uses of at-home care

Costs per at-home care user set at $¥ 1.32$ million

Total Cost $=¥ 1.32$ million $* 5.6$ million * $0.741+¥ 4.31$ million $* 5.6$ million * $0.200=¥ 10.30$ trillion

Case 3: Adjusting both the number of users of at-home care and cost of home care

Costs per institutional care user remain unchanged from 2001-2003 level (about $¥ 4.3$ million)

Costs per at-home care user rise $6.7 \%$ annually (actual 2001-03 growth rate) to attain $¥ 5.164$ million in 2025 .

Share of institutional care users set at $20.0 \%$ (vs $23.2 \%$ in $2001,21.2 \%$ in 2002 , and $20.0 \%$ in FY2003).

Share of at-home care user increases by $1.5 \%$ annually to attain $74.1 \%$ in 2025 (was $55.1 \%$ in $2001,57.0 \%$ in 2002 , and $57.6 \%$

Total Cost $=¥ 5.164$ million * 5.6 million * $0.741+¥ 4.31$ million * 5.6 million * $0.200=¥ 26.26$ trillion

Notes:

A Based on the medium variant (JNIPSSR 2003).

Based on JMHLW (2002).

$\checkmark$ Based on AJFNHIO (2003).

4 Based on Noguchi and Shimizutani (2003). 
Table 3. Historical Data: Elderly Persons (age 65+) in Japan Requiring Long-term Care

$\begin{array}{cccc} & \underline{\mathbf{1 9 9 3}} & \underline{\mathbf{1 9 9 6}} & \mathbf{1 9 9 8} \\ \text { In Care } & 4.947 & \mathbf{4 . 5 2 8} & 4.739 \\ \text { Conf. to Bed } & 0.793 & 0.694 & 0.684 \\ \text { Senile } & 0.917 & 0.794 & 0.807 \\ \text { Frail } & 2.249 & 2.077 & 2.077 \\ \text { Other Care } & 0.988 & 0.962 & 1.175\end{array}$

Source: JMHLW (various years) “Basic Survey on People’s Life”

Table 4: Current and Projected Number of Elderly Japanese Requiring LTC

\begin{tabular}{|c|c|c|c|c|c|c|c|}
\hline Estimated Millions of Persons: & 2000 (est) & Source & 2000 (actual) & & Source & $\underline{2025}$ & Source \\
\hline Elderly Persons & 21.7 & [a] & 22 & & [b] & 32.4 & [g] \\
\hline Elderly Persons Requiring LTC & 2.8 & [a] & 2.9 & * & [c] & 5.2 & [g] \\
\hline Elderly Bedridden & 1.2 & [a] & 0.4 & + & [d] & 2.3 & [g] \\
\hline Physically Weak Elderly & 1.3 & [a] & 1.15 & ++ & [e] & 2.6 & [g] \\
\hline Elderly with Dementia & 0.2 & [a] & 0.37 & +++ & [f] & 0.4 & [g] \\
\hline
\end{tabular}

Notes:

*In 2001

+This figure includes only the number of bedridden in institutions and excludes those living in houses.

++ Care levels 3-5 only.

+++ Care levels 3-5 in institutions only.

Sources:

[a] JMHLW (2000). "Survey on Care Service Providers"

[b] JMPMHAPT (2003)

[c] AJFNHIO (2003)

[d] Kaigo Service Shisetsu Jigyousho Chousa

[e] AJFNHIO (2003)

[f] Kaigo Service Shisetsu Jigyousho Chousa

[g] JMHLW (2002) 
Table 5. Descriptive Statistics Regarding LTC Capacity, Utilization, and Costs in Japan

\begin{tabular}{|l|c|c|c|c|}
\multicolumn{2}{c}{ Mean } & Min & Max & SD \\
\hline Panel A: Dependency Ratios & & & & \\
\hline Elderly/Working-age population & 0.311 & 0.194 & 0.428 & 0.057 \\
Entitled/Working-age population & 0.043 & 0.020 & 0.066 & 0.012 \\
Entitled/Elderly & 0.137 & 0.102 & 0.175 & 0.019 \\
\hline Panel B: Capacity & & & & \\
\hline Beds/000 Elderly & 32.489 & 21.590 & 49.645 & 6.910 \\
Beds/000 Eligible & 237.920 & 169.248 & 319.134 & 33.602 \\
\hline Panel C: Utilization Ratios & & & & \\
\hline Institutional care users/Elderly & 0.032 & 0.021 & 0.048 & 0.007 \\
At-home care users/Elderly & 0.076 & 0.054 & 0.103 & 0.011 \\
\hline Panel D: Cost Per Person (000 Yen/Year in 2000) & & & \\
\hline Inst. Cost/Instit. Care Users & 4327.696 & 4132.435 & 4643.209 & 114.177 \\
At-home cost/At-home care users & 1093.457 & 912.445 & 1297.436 & 88.821 \\
Total Cost/Total Care Users & 2041.579 & 1797.901 & 2449.080 & 136.837 \\
Total Cost/Total Elderly & 220.591 & 159.787 & 321.980 & 35.893 \\
\hline
\end{tabular}

Notes: Working-age=Age 15-64; Elderly=age 65+

Cost figures average 2001FY and 2002FY and are deflated by CPI

Sources: Authors' computations from data provided by the Ministry of Health, Labor and Welfare of Japc National Health Insurance Association of Japan; and Statistics Bureau of Japan 
Table 6: Multivariate Regression Results for LTC Entitlement and Utilization Rates

(t stats in parens)

\section{Population Density}

(000/km)

Healthcare Sector Earnings

(000 yen monthly, including bonus)

\section{Average Prefecture Earnings}

(000 yen annual, including bonus)

\section{Percent 75+}

(Pop75+/TotalPop)

\section{LTC Bed Availability}

(00 LTC Beds/Pop75+)

\section{NonLTCHospital Bed Availability} (00 NonLTCHospBed/Pop65+)

Constant

$\mathrm{R}^{* \star 2}$

Notes:

**Significant at $5 \%$ level

*Significant at $10 \%$ level

\begin{tabular}{|c|c|c|c|c|c|}
\hline \multicolumn{2}{|c|}{$\begin{array}{l}\text { Entitlement Rate } \\
\text { (\%Pop 65+ Entitled to } \\
\text { LTC/1000) }\end{array}$} & \multicolumn{2}{|c|}{$\begin{array}{c}\text { Home Care Utilization Rate } \\
\text { (\%Pop 65+ Utilizing Home } \\
\text { Care/1000) }\end{array}$} & \multicolumn{2}{|c|}{$\begin{array}{l}\text { Instit Care Utilization Rate } \\
\text { (\%Pop65+UsingInstitCare/1000) }\end{array}$} \\
\hline 1 & 2 & 3 & 4 & 5 & 6 \\
\hline 0.0067 & 0.0054 & 0.0038 & 0.0035 & 0.0010 & 0.0005 \\
\hline $3.29^{* *}$ & $3.05^{\star *}$ & $2.86^{* *}$ & $2.5595^{\star *}$ & 1.000 & $4.532^{* *}$ \\
\hline-0.0177 & -0.0110 & -0.0100 & -0.0080 & -0.0030 & 0.0004 \\
\hline $3.103^{* *}$ & $2.26^{* *}$ & $2.564^{* *}$ & $2.0751^{* *}$ & 1.441 & 1.169 \\
\hline-0.0116 & -0.0020 & -0.0070 & -0.0050 & -0.0060 & -0.0010 \\
\hline $2.121^{\star \star}$ & 0.488 & $1.8389^{*}$ & 1.208 & $3.3715^{\star *}$ & $2.6874^{\star *}$ \\
\hline 0.3450 & 0.2740 & 0.1570 & 0.1428 & 0.0999 & 0.0275 \\
\hline $2.5064^{* *}$ & $2.0398^{\star *}$ & $1.7418^{*}$ & 1.378 & $2.3045^{\star *}$ & $3.3911^{* *}$ \\
\hline & 0.1400 & & 0.0300 & & 0.0900 \\
\hline & $4.3234^{\star *}$ & & 1.225 & & $45.658^{\star *}$ \\
\hline & 0.0200 & & 0.0100 & & 0.0000 \\
\hline & 1.011 & & 0.324 & & 1.265 \\
\hline 0.233 & 0.110 & 0.132 & 0.104 & 0.060 & 0.000 \\
\hline $7.48^{* *}$ & $2.928^{* *}$ & $6.459^{* *}$ & $3.606^{* *}$ & $6.114^{* *}$ & 0.076 \\
\hline 0.410 & 0.581 & 0.296 & 0.306 & 0.463 & 0.986 \\
\hline
\end{tabular}


